\title{
Floristic study of Jogyesan Mt.
}

\section{Eun-Mi SUN, Seung-Man CHOI ${ }^{1}$, Byeol-Ah KIM², Hyun-Deok SON ${ }^{3}$, Hang-Hwa HONG ${ }^{1}$ and Hyoung-Tak IM ${ }^{1 *}$}

\author{
Forest Biodiversity Division, Korea National Arboretum, Pocheon 11186, Korea \\ ${ }^{1}$ Chonnam National University, Gwangju 61186, Korea \\ ${ }^{2}$ Central Regional Office of Forest Service, Korea Forest Service, Buyeo 33161, Korea \\ ${ }^{3}$ Mokpo Natural History Museum, Mokpo 58699, Korea
}

(Received 28 October 2018; Revised 20 December 2018; Accepted 24 December 2018)

\begin{abstract}
We investigated the flora of Jogyesan Mt. and discussed important vascular plants found on this mountain. In total, 16 separate field trips (20 days overall) were completed from 2013 to 2017 . There are 577 taxa on Mt. Jogyesan, consisting of 115 families, 333 genera, 520 species, 8 subspecies, 45 varieties, and 4 forms. Eighteen endemic plants of Korea were found on Jogyesan Mt., including Carex okamotoi Ohwi, Coreanomecon hylomeconoides Nakai, and Stewartia koreana Nakai ex Rehder. There are 80 taxa of floristic regional indicator plants in total, including level V such as Adenophora palustris Kom. and level IV such as Dryopteris championii (Benth.) C. Chr. ex Ching, Gastrodia elata Blume, Lindera sericea (Siebold \& Zucc.) Blume and Corylopsis glabrescens var. gotoana (Makino) T. Yamanaka. There also are 24 taxa of naturalized plants, including Ambrosia artemisiifolia L.
\end{abstract}

Keywords: Jogyesan Mt., flora, floristic regional indicator plants, endemic plants, naturalized plants

조계산은 북위 $35^{\circ} 00^{\prime}$, 동경 $121^{\circ} 19^{\prime}$ 에 위치하는 해발 $884 \mathrm{~m}$ 의 산으로, 행정구역상으로는 전라남도 순천시 송 광면, 주암면, 승주읍에 걸쳐있다. 지리산 노고단의 남서 쪽 $40 \mathrm{~km}$ 거리에 있으며, $20 \mathrm{~km}$ 거리에 고흥군 여자만이 있다. 전남 지역의 산으로는 광주 무등산, 영암 월출산 다 음으로 산체가 큰 산으로 크고 작은 계곡이 잘 발달되어 있다. 동쪽의 선암사 계곡은 상사호에 이르고, 서쪽의 송 광사 계곡은 주암호에 이른다. 송광사는 국내 삼대 사찰 중 하나인 승보사찰로 유명하고, 선암사는 한국불교 태고 종의 총림으로 승가대학이 있다. 전라남도의 산악지대는 한국동란 이후 1960 년대에 이르기까지 땔감 공급을 위해 과도하게 벌채되었으며, 현재의 숲은 대부분이 그 이후 조성된 유령림이다. 조계산은 동서의 주된 접근로에 송광 사와 선암사가 있어서 산림 파괴의 영향이 상대적으로 적 었으며, 1979년 이후 도립공원으로 지정되어서 자연환경 이 잘 보존되어 있다. 계곡 하부를 중심으로 삼나무, 편백 림이 조성되어 있고, 일부 조릿대가 번성한 지역도 있으 나 임상식물의 발달은 양호한 편이다. 온도분포에 의한 구분에 의하면 조계산은 난온대와 냉온대의 경계에 위치
하며 식물지리학상으로는 온대하부에 해당한다. 조계산 식물상에 대한 기존 연구는 없으며, 1998년 환경부 전국 자연환경조사의 보성, 순천지역 식물상 목록의 일부로 조 계산 식물이 포함되어 있다 (85과 274속 334종 39변종 5품 종의 378종류) (Im and Hong, 1998). 본 연구는 조계산의 식 물상을 밝히고 그 식물지리학적 중요성을 논하는 데에 그 목적이 있다.

\section{재료 및 방법}

현지조사는 2013년 4월부터 2017년 8월까지 총 16회(20 일)에 걸쳐 이루어졌다(Table 1). 조사범위는 조계산의 주 봉인 장군봉 $(884 \mathrm{~m})$ 을 중심으로 송광사-접치-선암사-장 안천-천자암을 포함하였으며, 주요 조사 경로는 Fig. 1과 같다. 조사 중에 확인된 모든 출현종을 채집하였으며, 오 랜 기간 널리 조림되어 온 식물 또는 자생하게 된 외래식 물(귀화식물) 이외의 재배식물은 제외시켰다. 채집된 식 물은 흡습지와 건조기를 이용하여 건조시켰으며, 확증표 본은 전남대학교 생물학과 표본실 $(\mathrm{CNU})$ 에 보관하였다.

\footnotetext{
*Author for correspondence: ihtplant@hanmail.net
} 
Table 1. Surveyed dates and routes.

\begin{tabular}{ll}
\hline \hline \multicolumn{1}{c}{ Date } & \multicolumn{1}{c}{ Surveyed routes } \\
\hline 4 Apr 2013 & Sangyeoeup-Cheonja-am (shrine)-Gulmok-je (pass) \\
27-28 Apr 2013 & Jeopchi-Odu-je (pass)/Jeopchi-Jangbak wetland \\
28 Jun 2013 & Jeopchi-Jangbak wetland-Jogyesan Mt. \\
14-15 Jul 2013 & Seonam-sa (temple)-Gulmok-je (pass)-Cheonja-am (shrine) \\
10 Aug 2013 & Songgwang-sa (temple)-Gulmok-je (pass)-Yeonsan-bong (peak) \\
10 Sep 2013 & Sangyeoeup-Cheonja-am (shrine)-Gulmok-je (pass) \\
8 Aug 2013 & Jangan-cheon (river)-Jangbak wetland \\
14 Aug 2013 & Jeopchi-Odu-je (pass) \\
1 Apr 2017 & Jeopchi-Jangbak wetland-Jogyesan Mt. \\
15 Apr 2017 & Seonam-sa (temple)-Gulmok-je (pass)-Jogyesan Mt. \\
19-20 May 2017 & Songgwang-sa (temple)-Gulmok-je (pass)-Jogyesan Mt. \\
27-28 May 2017 & Seonam-sa (temple)-Gulmok-je (pass)-Jogyesan Mt. \\
7 Jun 2017 & Seonam-sa (temple)-Gulmok-je (pass)-Jogyesan Mt. \\
27 Jun 2017 & Jangan-cheon (river)-Jangbak wetland \\
19 Jul 2017 & Songgwang-sa (temple)-Gulmok-je (pass)-Jangbak wetland \\
16 Aug 2017 & Seonam-sa (temple)-Gulmok-je (pass)-Jangbak wetland \\
\hline
\end{tabular}
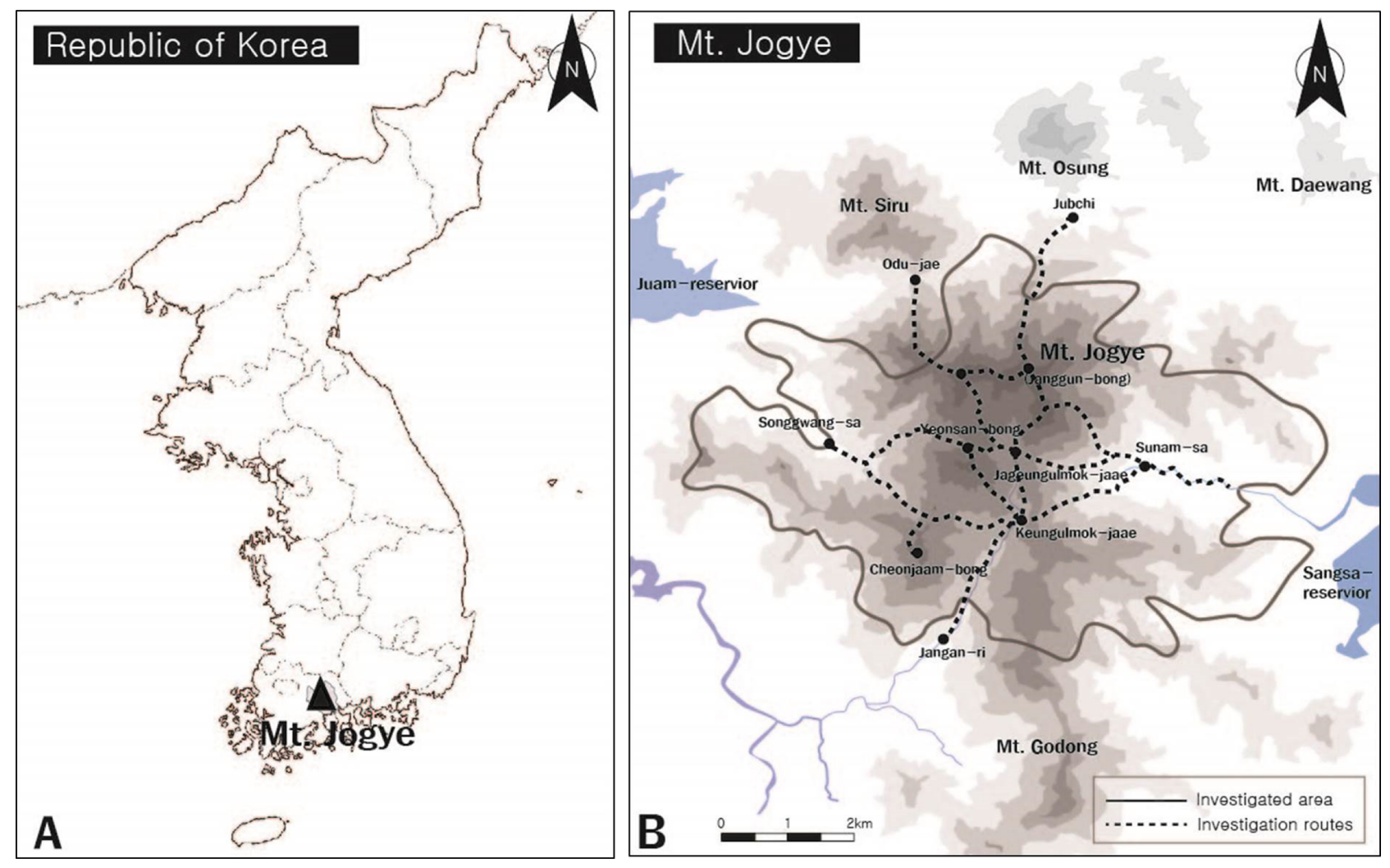

Fig. 1. Map of investigated area (A) and route (B). 
식물목록 작성에 있어서 본 조사에서 채집된 식물은 물론 $\mathrm{CNU}$ 에 소장되어 있는 조계산 표본도 포함하였다. 식물의 동정은 Lee (1996), Lee (2006), Park (1995, 2001), Tagawa (1959), Kitamura and Murata (1982), Iwatsuki (1992), Nagata (1989) 등의 도감을 이용하였다. 과의 배열은 The Genera of Vascular Plants of Korea (Park, 2007)에 따랐고, 과내에서 는 알파벳 순서로 속명과 종명을 정리하였으며, 학명은 국가표준식물목록(Korea National Arboretum and the Korean Society of Plant Taxonomists, 2007)을 따랐다. 작성 된 식물목록을 한반도특산식물목록(Chung et al. 2017), 희 귀식물목록(Korea National Arboretum, 2008), 적색목록 (National Institute of Biological Resources, 2012), 식물구계 학적 특정식물목록(Ministry of Environment, 2012)에 근거 하여 분석하였다(Appendix 1).

\section{결과 및 고찰}

조계산 지역에서는 115 과 333 속 520 종 8 아종 45 변종 4 품종 총 577분류군이 확인되었다(Table 2). 이는 국내 관속 식물 4,338 분류군(Lee et al., 2011)의 13.4\%에 해당되며, 이 중 양치식물은 13 과 19 속 40 종 1 변종의 총 41 분류군 (7.1\%), 나자식물은 3 과 4 속 4종의 총 4 분류군 $(0.7 \%)$ 으로 확인되었다. 피자식물 중 쌍자엽식물은 87 과 242속 364종 7 아종 33 변종 4 품종의 총 408 분류군(70.6\%), 단자엽식물
은 12 과 68 속 112 종 1 아종 11 변종의 총 124 분류군( $21.6 \%)$ 으로 나타났다.

\section{특산식물}

본 조사지역에서 확인된 577분류군 중 특산식물은 큰설 설고사리(Phegopteris koreana), 지리대사초(Carex okamotoi), 매미꽃(Coreanomecon hylomeconoides), 노각나무(Stewartia koreana) 등 총 12 과 17 속 18 분류군이다(Table 3). 조사된 18 분류군은 우리나라 특산식물 328 분류군(Korea Forest Service, 2015)의 5.2\%에 해당된다. 매미꽃은 지리산을 중 심으로 한 전남, 경남의 깊은 산지 계곡부 및 습지에 무리 지어 자라는데, 전남의 경우 보성, 화순, 영광까지 분포하 며, 조계산 전역의 그늘진 계곡부에 흔히 볼 수 있다. 특히 접치마을-오두재 구간과 송광사-선암사 구간의 등산로

Table 2. The number of vascular plants in Jogyesan Mt..

\begin{tabular}{lcccccc}
\hline \hline \multicolumn{1}{c}{ Rank } & Fam. & Gen. & Sp. & Subsp. & Var. & For. \\
\hline Pteriodophyta & 13 & 19 & 40 & 0 & 1 & 0 \\
Gymnospermae & 3 & 4 & 4 & 0 & 0 & 0 \\
Angiospermae & 99 & 310 & 476 & 8 & 44 & 4 \\
Dicotyledonae & 87 & 242 & 364 & 7 & 33 & 4 \\
Monocotyledonae & 12 & 68 & 112 & 1 & 11 & 0 \\
Total & 115 & 333 & 520 & 8 & 45 & 4 \\
\hline
\end{tabular}

Table 3. The list of endemic plants to Korea in Jogyesan Mt..

\begin{tabular}{ll}
\hline \hline \multicolumn{1}{c}{ Family } & \multicolumn{1}{c}{ Species } \\
\hline Thelypteridaceae 처녀고사리과 & Phegopteris koreana B. Y. Sun \& C. H. Kim 큰설설고사리 \\
Ranunculaceae 미나리아재비과 & Thalictrum actaefolium var. brevistylum Nakai 은뀡의다리 \\
Papaveraceae 양귀비과 & Coreanomecon hylomeconoides Nakai 매미꽃 \\
Polygonaceae 마디풀과 & Stewartia koreana Nakai ex Rehder 노각나무 \\
Salicaceae 버드나무과 & Salix hallaisanensis H. Lev. 떡버들 \\
Ericaceae 진달래과 & Vaccinium hirtum var. koreanum (Nakai) Kitam. 산앵도나무 \\
Rosaceae 장미과 & Potentilla dickinsii var. breviseta Nakai 참양지꽃 \\
Leguminosae 콩과 & Indigofera koreana Ohwi 민땅비싸리 \\
Labiatae 꿀풀과 & Vicia hirticalycina Nakai 나래완두 \\
Oleaceae 물푸레나무과 & Scutellaria insignis Nakai 광릉골무꽃 \\
Diervillaceae 병꽃나무과 & Forsythia koreana (Rehder) Nakai 개나리 (식재) \\
Compositae 국화과 & Weigela subsessilis (Nakai) L. H. Bailey 병꽃나무 \\
& Aster koraiensis Nakai 벌개미취 \\
Cirsium setidens (Dunn) Nakai 고려엉겅퀴 \\
Cyperaceae 사초과 & Saussurea macrolepis (Nakai) Kitam. 각시서덜취 \\
Liliaceae 백합과 & Carex erythrobasis H. Lev. \& Vaniot 한라사초 \\
\hline & Carex okamotoi Ohwi 지리대사초 \\
Hosta minor (Baker) Nakai 좀비비추
\end{tabular}


Table 4. The list of specially designated plants in Jogyesan Mt. by Ministry of Environment (2012).

\begin{tabular}{|c|c|c|}
\hline & & Species \\
\hline \multirow[t]{2}{*}{$\mathrm{V}$} & Campanulaceae & Adenophora palustris Kom. 진퍼리잔대 \\
\hline & Saururaceae & Houttuynia cordata Thunb. 약모밀 (식재) \\
\hline \multirow[t]{6}{*}{ IV } & Dryopteridaceae & Dryopteris championii (Benth.) C. Chr. ex Ching 제주지네고사리 \\
\hline & Lauraceae & Lindera sericea (Siebold \& Zucc.) Blume 털조장나무 \\
\hline & Papaveraceae & Coreanomecon hylomeconoides Nakai 매미꽃 \\
\hline & Hamamelidaceae & Corylopsis glabrescens var. gotoana (Makino) T. Yamanaka 히어리 \\
\hline & Cyperaceae & Carex ligulata var. austrokoreensis Ohwi 갈사초 \\
\hline & Orchidaceae & Gastrodia elata Blume 천마 \\
\hline \multirow[t]{16}{*}{ III } & Orchidaceae & Cremastra appendiculata (D. Don) Makino 약난초 \\
\hline & Monotropaceae & Monotropa uniflora L. 수정난풀 \\
\hline & Thelypteridaceae & Phegopteris koreana B. Y. Sun \& C. H. Kim 큰설설고사리 \\
\hline & Ranunculaceae & Aconitum longecassidatum Nakai 흰진범 \\
\hline & Theaceae & Stewartia koreana Nakai ex Rehder 노각나무 \\
\hline & Flacourtiaceae & Idesia polycarpa Maxim. 이나무 \\
\hline & Salicaceae & Salix purpurea var. smithiana Trautv. 당키버들 \\
\hline & Hydrangeaceae & Philadelphus pekinensis Rupr. 애기고광나무 \\
\hline & Fabaceae & Rhynchosia acuminatifolia Makino 큰여우콩 \\
\hline & Aceraceae & Acer palmatum Thunb. 단풍나무 \\
\hline & Apiaceae & Sanicula tuberculata Maxim. 애기참반디 \\
\hline & Lamiaceae & Salvia japonica Thunb. 둥근배암차즈기 \\
\hline & Lamiaceae & Scutellaria insignis Nakai 광릉골무꽃 \\
\hline & Cyperaceae & Carex gifuensis Franch. 애기감둥사초 \\
\hline & Liliaceae & Aletris spicata (Thunb.) Franch. 쥐꼬리풀 \\
\hline & Liliaceae & Lilium leichtlinii var. maximowiczii (Regel) Baker 중나리 \\
\hline \multirow[t]{19}{*}{ II } & Thelypteridaceae & Macrothelypteris oligophlebia var. elegans (Koidz.) Ching 각시고사리 \\
\hline & Berberidaceae & Aquilegia buergeriana var. oxysepala (Trautv. \& Meyer) Kitam. 매발톱 \\
\hline & Ranunculaceae & Caltha palustris L. 동의나물 \\
\hline & Berberidaceae & Caulophyllum robustum Maxim. 꿩의다리아재비 \\
\hline & Violaceae & Viola orientalis (Maxim.) W. Becker 노랑제비꽃 \\
\hline & Violaceae & Viola tokubuchiana var. takedana (Makino) F. Maek. 민둥뫼제비꽃 \\
\hline & Ericaceae & Vaccinium hirtum var. koreanum (Nakai) Kitam. 산앵도나무 \\
\hline & Primulaceae & Primula sieboldii E. Morren 앵초 \\
\hline & Rosaceae & Potentilla dickinsii Franch. \& Sav. 돌양지꽃 \\
\hline & Celastraceae & Euonymus maackii Rupr. 좁은잎참빗살나무 \\
\hline & Apiaceae & Cymopterus melanotilingia (H. Boissieu) C. Y. Yoon 큰참나물 \\
\hline & Cucurbitaceae & Melothria japonica (Thunb.) Maxim. ex Cogn. 새박 \\
\hline & Campanulaceae & Lobelia sessilifolia Lamb. 숫잔대 \\
\hline & Adoxaceae & Adoxa moschatella L. 연복초 \\
\hline & Asteraceae & Ainsliaea apiculata Sch. Bip. Ex Zoll. 좀딱취 \\
\hline & Asteraceae & Cirsium setidens (Dunn) Nakai 고려엉겅퀴 \\
\hline & Asteraceae & Ligularia fischeri (Ledeb.) Turcz. 곰취 \\
\hline & Asteraceae & Saussurea macrolepis (Nakai) Kitam. 각시서덜취 \\
\hline & Acoraceae & Acorus gramineus Sol. ex Aiton Hort. 석창포 \\
\hline
\end{tabular}


Table 4. Continued.

\begin{tabular}{|c|c|c|}
\hline & & Species \\
\hline \multirow[t]{6}{*}{ II } & Cyperaceae & Carex erythrobasis H. Lev. \& Vaniot 한라사초 \\
\hline & Cyperaceae & Carex okamotoi Ohwi 지리대사초 \\
\hline & Iridaceae & Iris ensata var. sponteana (Makino) Nakai 꽃창포 \\
\hline & Iridaceae & Iris minutoaurea Makino 금붓꽃 \\
\hline & Orchidaceae & Epipactis thunbergii A. Gray 닭의난초 \\
\hline & Orchidaceae & Platanthera ussuriensis (Regel \& Maack) Maxim. 나도잠자리난초 \\
\hline \multirow[t]{29}{*}{ I } & Thelypteridaceae & Thelypteris glanduligera (Kunze) Ching 사다리고사리 \\
\hline & Dryopteridaceae & Cyrtomium fortunei J. Sm. 쇠고비 \\
\hline & Dryopteridaceae & Dryopteris crassirhizoma Nakai 관중 \\
\hline & Dryopteridaceae & Dryopteris erythrosora (D. C .Eaton) Kuntze 홍지네고사리 \\
\hline & Dryopteridaceae & Dryopteris uniformis (Makino) Makino 곰비늘고사리 \\
\hline & Taxaceae & Cephalotaxus harringtonia (Knight ex Forbes) K. Koch 개비자나무 \\
\hline & Chloranthaceae & Chloranthus fortunei (A. Gray) Sloms 옥녀꽃대 \\
\hline & Ranunculaceae & Aconitum jaluense Kom. 투구꽃 \\
\hline & Ranunculaceae & Clematis patens C. Morren \& Decne. 큰꽃으아리 \\
\hline & Ranunculaceae & Semiaquilegia adoxoides (DC.)Makino 개구리발톱 \\
\hline & Sabiaceae & Meliosma myriantha Siebold \& Zucc. 나도밤나무 \\
\hline & Sabiaceae & Meliosma oldhamii Miq. ex Maxim. 합다리나무 \\
\hline & Celidaceae & Aphananthe aspera (Thunb.) Planch. 푸조나무 \\
\hline & Juglandaceae & Juglans mandshurica Maxim. 가래나무 \\
\hline & Caryophyllaceae & Lychnis cognata Maxim. 동자꽃 \\
\hline & Tiliaceae & Grewia parviflora Bunge 장구밥나무 \\
\hline & Salicaceae & Salix chaenomeloides Kimura 왕버들 \\
\hline & Ericaceae & Vaccinium oldhamii Miq. 정금나무 \\
\hline & Onagraceae & Circaea lutetiana subsp. quadrisulcata (Maxim.) Asch. \& Magnus 털이슬 \\
\hline & Staphyleaceae & Euscaphis japonica (Thunb.) Kanitz 말오줌때 \\
\hline & Rutaceae & Orixa japonica Thunb. 상산 \\
\hline & Balsaminaceae & Impatiens nolitangere L. 노랑물봉선 \\
\hline & Araliaceae & Eleutherococcus sessiliflorus (Rupr. \& Maxim.) S. Y. Hu 오갈피나무 \\
\hline & Lamiaceae & Clinopodium micranthum (Regel) H. Hara 두메층층이 \\
\hline & Lamiaceae & Lycopus maackianus Makino 애기쉽싸리 \\
\hline & Cyperaceae & Carex nervata Franch. \& Sav. 양지사초 \\
\hline & Liliaceae & Erythronium japonicum Decne. 얼레지 \\
\hline & Liliaceae & Hosta capitata (Koidz.) Nakai 일 월비비추 \\
\hline & Liliaceae & Hosta minor (Baker) Nakai 좀비비추 \\
\hline
\end{tabular}

및 계곡부를 따라 많이 분포한다. 지리대사초는 백두대간 을 중심으로 자연도 높은 산지대 임상에 자라는데, 조계 산의 경우 장군봉과 장박습지 주변의 임내 사면에 대군락 을 이루고 있다.

\section{중요식물}

1. 식물구계학적 특정식물

조계산에서 확인된 환경부 지정 식물구계학적 특정
식물종은 총 81 분류군으로 조계산에서 확인된 관속식 물 총 577 분류군의 $14 \%$ 에 해당한다(Table 4). 이들은 진 퍼리잔대(Adenophora palustris)를 비롯한 $\mathrm{V}$ 등급종 2 분 류군, 천마(Gastrodia elata) 등 IV등급종 6분류군, III등 급종인 약난초(Cremastra appendiculata) 등 16분류군, II 등급종으로 금붓꽃(Iris minutoaurea) 등 25 분류군, I등 급종으로 사다리고사리(Thelypteris glanduligera) 등 29 분류군이 확인되었다. 진퍼리잔대는 강원도 영월, 충남 
서산시 가야산, 전북 남원군 지리산 등 매우 한정된 지 역에 국한되어 있다. 조계산에는 장박습지 부근 초지에 드물게 자란다. 약난초는 전남과 경남의 깊은 산 계곡부 에 제한적으로 분포하는 다년초로 부식층이 깊고 습기 많으며 어두운 임상에 자란다. 조계산에는 선암사와 운 수암 사이의 계곡부에서 확인되었다. 뻐꾹나리(Tricyrtis macropoda)는 전남북, 경남을 중심으로 충청, 경부까지 분포하며, 습기가 있고 광환경이 좋은 임염부에 잘 자라 는 다년초로, 조계산의 경우 굴목제 주변의 계곡부 및

Table 5. The list of endangered species in Jogyesan Mt. designated by National Institute of Biological Resources.

Grade $\quad$ Species

EN Campanulaceae Adenophora palustris Kom. 진퍼리잔대

NT Orchidaceae Cremastra appendiculata (D. Don) Makino 약난초

NE Cyperaceae Carex ligulata var. austrokoreensis Ohwi 갈사초 EN, Endangered; NT, Near Threatened; NE, Not Evaluated
임연부에 특히 많이 자란다.

2. 한국멸종위기 야생식물 적색자료

멸종위기 야생식물로는 위기종(endangered, EN)인 진 퍼리잔대, 준위협종(near threatedned, NT)인 약난초, 자료 부족종(data deficient, $\mathrm{DD}$ )인 갈사초(carex ligulata var. austrokoreensis)가 확인되었다(Table 5).

\section{3. 귀화식물}

생태계교란식물인 돼지풀(Ambrosia artemisiifolia)을 포 함하여 총 24 분류군의 귀화식물을 확인하였다(Table 6). 이는 우리나라 귀화식물 321분류군(Park, 1995)의 7.5\%에 해당한다. 인접한 화순 백아산의 귀화율 $10.3 \%$ (Seon et al., 2017)에 비하면 귀화식물이 상대적으로 적은데, 이는 조 계산이 도립공원이고 주된 등산로의 양쪽 입구에 송광사 와 선암사라는 고찰이 있어서 다른 지역에 비해 자연도가 높기 때문으로 추정된다.

Table 6. The list of naturalized plants in Jogyesan Mt.

\begin{tabular}{|c|c|}
\hline Family & Species \\
\hline Phytolacaceae 자리공과 & Phytolacca americana L. 미국자리공 \\
\hline Chenopodiaceae 명아주과 & Chenopodium ficifolium $\mathrm{Sm}$. 좀명아주 \\
\hline \multirow[t]{2}{*}{ Polygonaceae 마디풀과 } & Fallopia dentatoalata (F. Schmidt) Holub 큰닭의덩굴 \\
\hline & Rumex crispus L. 소리쟁이 \\
\hline Cruciferae 십자화과 & Lepidium vvirginicum L. 콩다닥냉이 \\
\hline Rosaceae 장미과 & Potentilla amurensis Maxim. 좀개소시랑개비 \\
\hline \multirow[t]{3}{*}{ Leguminosae 콩과 } & Amorpha fruticosa L. 족제비싸리 \\
\hline & Astragalus sinicus L. 자운영 \\
\hline & Vicia dasycarpa Ten. 각시갈퀴나물 \\
\hline \multirow[t]{2}{*}{ Onagaceae 바늘꽃과 } & Oenothera glazioviana Micheli 큰달맞이꽃 \\
\hline & Oenothera odorata Jacq. 달맞이꽃 \\
\hline \multirow[t]{3}{*}{ Scrophulariaceae 현삼과 } & Veronica arvensis L. 선개불알풀 \\
\hline & Veronica hederaefolia L. 눈개불알풀 \\
\hline & Veronica persica Poir. 큰개불알풀 \\
\hline \multirow[t]{6}{*}{ Compositae 국화과 } & Ambrosia artemisiifolia L. 돼지풀 \\
\hline & Bidens frondosa L. 미국가막사리 \\
\hline & Conyza canadensis (L.) Cronquist 망초 \\
\hline & Crassocephalum crepidioides (Benth.) S. Moore 주홍서나물 \\
\hline & Erigeron annuus (L.) Pers. 개망초 \\
\hline & Galinsoga quadriradiata Ruiz \& Pav. 털별 꽃아재비 \\
\hline \multirow[t]{4}{*}{ Graminae 벼과 } & Dactylis glomerata L. 오리새 \\
\hline & Eragrostis curvula (Schrad.) Nees 능수참새그령 \\
\hline & Festuca myuros L. 들묵새 \\
\hline & Lolium multiflorum Lam. 쥐보리 \\
\hline
\end{tabular}




\section{조계산의 식물분류학적 중요성}

조계산은 우리나라 남부지방 산지 식물의 중심이 되는 지리산과 광주 무등산, 광양 백운산을 연결하는 위치에 있다. 지리산을 중심으로 하는 대표적 식물로는 히어리 (Corylopsis glabrescens var. gotoana), 매미꽃, 털조장나무 (Lindera sericea)를 들 수 있는데, 이들 식물은 조계산 전역 에 걸쳐 왕성한 생육을 보이고 있다. 특히 히어리는 송광 사 근처가 type locality로서 송광납판화(Coryopsis coreana
Uyeki)라는 이름으로 최초 보고되어 우리나라 고유종으 로 인식되기도 했으나, 현재는 일본의 큐슈, 시코쿠에 분 포하는 식물과 동일 분류군으로 인식되고 있다. 장박골의 상류에 있는 장박습지는 전남지방의 몇 개 안되는 산지습 지로서 진퍼리잔대, 애기참반디(Sanicula tuberculata), 광 릉골무꽃(Scutellaria insignis), 각시서덜취(Saussurea macrolepis), 갈사초, 흰진범(Aconitum longecassidatum), 뻐 꾹나리, 금붓꽃, 닭의난초(Epipactis thunbergii), 나도잠자
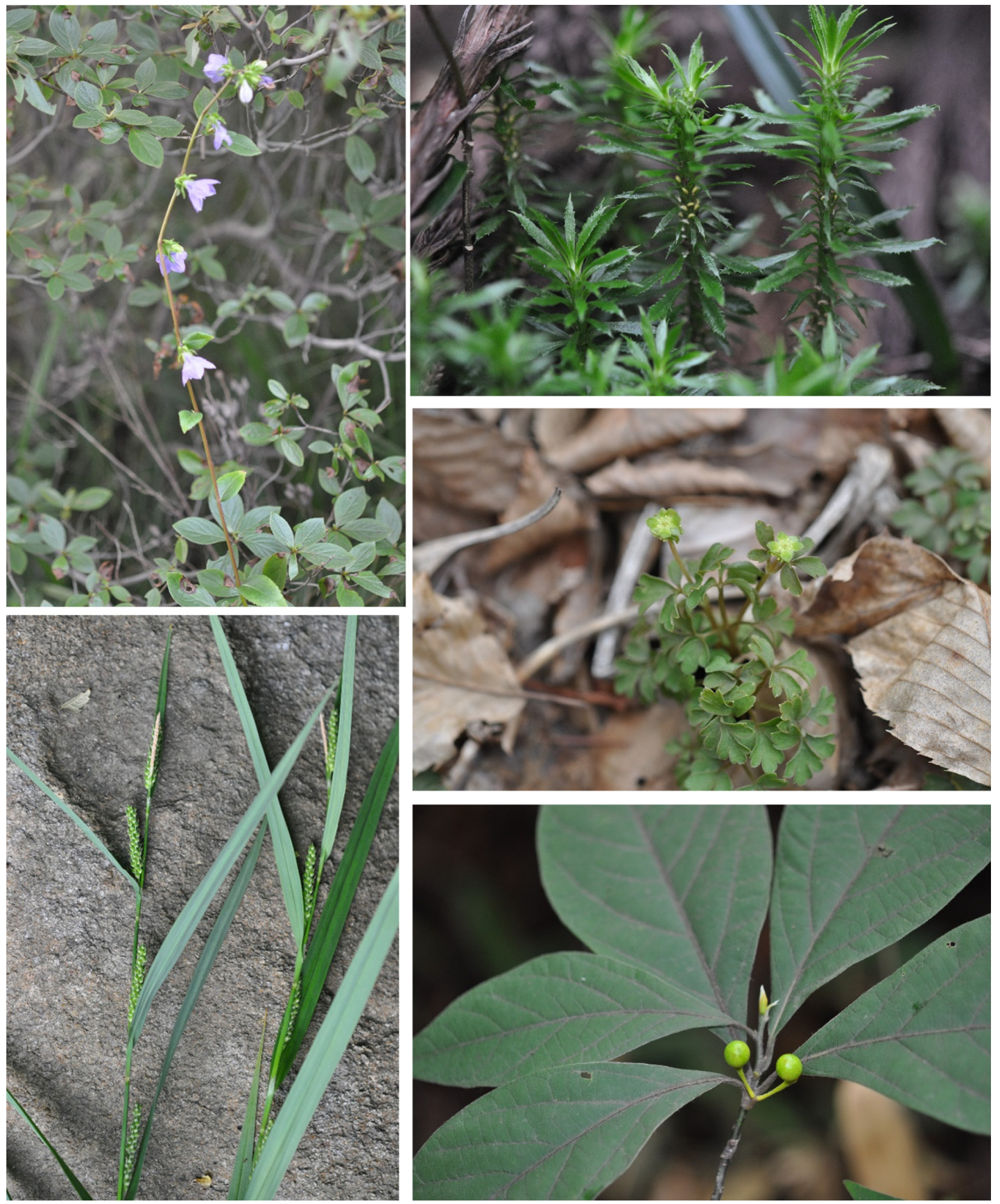

Fig. 2. Rare plant species of Jogyesan Mt. A. Adenophora palustris Kom. B. Carex ligulata Nees. C. Lycopodium serratum Thunb. D. Adoxa moschatellina L. E. Lindera sericea (Siebold \& Zucc.) Blume. 
리난초(Platanthera ussuriensis) 등의 희귀식물을 볼 수 있 는 조계산 식물상의 핵심지역이다(Fig. 2).

\section{Acknowledgments}

This research was supported by Grant No. NIBR201501202 from the National Institute of Biological Resources under the Ministry of Environment, Republic of Korea.

\section{Conflict of Interest}

The authors declare that there are no conflicts of interest.

\section{Literature Cited}

Chung, G Y., K. S. Chang, J.-M. Chung, H. J. Choi, W.-K. Paik and J.-O. Hyun. 2017. A checklist of endemic plants on the Korean Peninsula. Korean Journal of Plant Taxonomy 47: 264-288. (in Korean)

Im, H. T. and H. H. Hong. 1998. Flora of Jogyesan Mt. In Environment of Boseong-Suncheon (8-16). Ministry of Environment. Pp. 69-78. (in Korean)

Iwatwsuki, K. 1992. Wild Plant in Japan. Heibonsya, Tokyo. Pp. 182-201. (in Japanese)

Kitamura, S. and G. Murata. 1982. Coloured Illustrations of Woody Plants of Japan. Hoikusha Publishing Co., Osaka, 401 pp. (in Japanese)

Korea Forest Service. 2015. Act on the creation and furtherance of arboretums and gardens. Act No. 132027.

Korea National Arboretum. 2008. Rare Plants Data Book in Korea. Korea National Arboretum, Pocheon, 332 pp (in Korean).

Korea National Arboretum and The Plant Taxonomic Society of Korea. 2007. A Synonymic List of Vascular Plants in Korea.
Korea National Arboretum, Pocheon, 534 pp. (in Korean) Lee, B. Y., G, H. Nam, J. Y. Lee, C. H. Park, C. E. Lim, M. H. Kim, S. J. Lee, T. K. Noh, J. A. Lim, J. E. Han and J. H. Kim. 2011. National List of Species of Korea (Vascular Plants). National Institute of Biological Resources, Incheon, 933 pp. (in Korean)

Lee, T. B. 2006. Coloured Flora of Korea, Vol. I, II. Hyangmunsa, Seoul, Vol. 1, 914 pp, Vol. 2, 910 pp. (in Korean)

Lee, W. T. 1996. Coloured Standard Illustrations of Korean Plants. Academy Publishing Co., Seoul, 624 pp. (in Korean)

Lee, Y. N. 2006. New Flora of Korea, Vol. I, II. Kyohak Publishing Co., Ltd., Seoul, Vol. 1, 975 pp, Vol. 2, 885 pp. (in Korean)

Ministry of Environment. 2012. Forth Round of the National Natural Environmental Research Guidelines. Ministry of Environment and National Institute of Environmental Research, Gwacheon and Incheon. Pp. 173-226. (in Korean)

Nagata, T. 1989. Japanese Gramineae. Heibonsya, Tokyo, 388 pp. (in Japanese)

National Institute of Biological Resources. 2012. Red Data Book of Endangered Vascular Plants in Korea. Econature, Seoul, 174 pp. (in Korean)

Park, C.-W. 2007. The Genera of Vascular Plants of Korea. Flora of Korea Editorial Committee. Academy Publishing Co., Seoul, 1482 pp.

Park, S. H. 1995. Colored Illustrations of Naturalized Plants of Korea. Ilchokak, Seoul, 371 pp. (in Korean)

Park, S. H. 2001. Colored Illustrations of Naturalized Plants of Korea (Appendix). Ilchokak, Seoul, 178 pp. (in Korean)

Seon, E.-M., B.-A. Kim, H.-D. Son, J.-C. Jeong and H.-T. Im. 2017. Floristic study of Mt. Baekasan. Korean Journnal of Plant Taxonomy 47: 236-263. (in Korean)

Tagawa, M. 1959. Fems and Fern Allies of Japan. Hoikusya, Osaka, pp. 90-105. (in Japanese).

\title{
조계산의 식물상
}

\author{
선은미 · 최승만 ${ }^{1} \cdot$ 김별아 $^{2} \cdot$ 손현덕 $^{3} \cdot$ 홍행화 $^{1} \cdot$ 임형탁 $^{1 *}$
}

국립수목원, ${ }^{1}$ 전남대학교 자연과학대학 생물학과, ${ }^{2}$ 중부지방산림청, 부여국유림관리소, ${ }^{3}$ 목포자연사박물관

적 요. 전라남도 순천시에 위치한 조계산의 관속식물상을 조사하고 분포가 확인된 주요식물에 대해 논의하였다. 2013년 4월부터 2017년 8월까지 총 16회(20일)에 걸친 현지조사에서 확보된 표본과 전남대 생물학과 표본실(CNU) 의 수장표본에 근거하여 관속식물목록을 작성하였다. 조계산에서 115 과 333 속 520 종 8 아종 45 변종 4 품종 총 577 분류군을 확인하였다. 한국특산식물로는 지리대사초, 매미꽃, 노각나무 등 18 분류군으로 조사되었고 환경부지정 식물구계학적 특정식물종으로는 진퍼리잔대를 비롯한 $\mathrm{V}$ 등급종 2 분류군, 제주지네고사리, 털조장나무, 천마, 히어 리 등 IV등급종 6 분류군, III등급종인 약난초 등 16 분류군, II등급종으로 금붓꽃 등 25 분류군, I등급종으로 사다리 고사리 등 29 분류군이 확인되었다. 생태계교란식물인 돼지풀을 포함하여 총 24 분류군의 귀화식물이 확인되었다.

주요어: 조계산, 식물상, 식물구계학적특정식물, 특산식물, 귀화식물 
Appendix 1. List of vascular plants distributed in Jogyesan Mt.

Lycopodiaceae 석송과

Huperzia serrata (Thunb.) Trevis.

Equisetaceae 속새과

Equisetum arvense L.

Equisetum ramosissimum Desf.

Ophioglossaceae 고사리삼과

Botrychium ternatum (Thunb.) Sw.

Osmundaceae 고비과

Osmunda japonica Thunb.

Dennstaedtiaceae 잔고사리과

Dennstaedtia hirsuta (Sw.) Mett. ex Miq.

Dennstaedtia wilfordii (T. Moore) H. Christ

Aspleniaceae 꼬리고사리과

Asplenium incisum Thunb.

Asplenium ruprechtii S. Kurata

Onocleaceae 야산고비과

Pentarhizidium orientale (Hook.) Hayata

Woodsiaceae 우드풀과

Woodsia manchuriensis Hook.

Athyriaceae 개고사리과

Athyrium niponicum (Mett.) Hance

Athyrium vidalii (Franch. \& Sav.) Nakai

Athyrium yokoscense (Franch. \& Sav.) H. Christ

Cornopteris crenulatoserrulata (Makino) Nakai

Deparia angustatum (Nakai) Nakaike

Deparia conilii (Franch. \& Sav.) M. Kato

Deparia japonica (Thunb.) M. Kato

Deparia pycnosora (H. Christ) M. Kato

Thelypteridaceae 처녀고사리과

Macrothelypteris oligophlebia var. elegans (Koidz.) Ching

Phegopteris decursive-pinnata (H. C. Hall) Fee

Phegopteris koreana B. Y. Sun \& C. H. Kim

Thelypteris glanduligera (Kunze) Ching

Thelypteris japonica (Baker) Ching

Thelypteris palustris (A. Gray) Schott

\section{Dryopteridaceae 관중과}

Cyrtomium fortunei J. Sm.

Dryopteris bissetiana (Baker) C. Chr.

Dryopteris championii (Benth.) C. Chr. ex Ching

Dryopteris chinensis (Baker) Koidz.

Dryopteris crassirhizoma Nakai

뱀톱

P 150635

$\begin{array}{cc}\text { 쇠뜨기 } & \mathrm{E} 41524 \\ \text { 개속새 } & \mathrm{C} 0563 \\ \text { 고사리삼 } & \mathrm{E} 41525 \\ \text { 고비 } & \mathrm{C} 135087\end{array}$

잔고사리

I 008227

황고사리

P 150631

꼬리고사리

C 0595

거미고사리

P 150221

개면마

P 150652

만주우드풀

$$
\text { 개고사리 }
$$

I 008252

산개고사리

I 008219

뱀고사리

A 151254

응달고사리

I 008239

개좀진고사리

C 172168

좀진고사리

C 135391

진고사리

I 008248

털고사리

P 150467

$\begin{array}{cc}\text { 각시고사리 } & \text { A } 010404 \\ \text { 설설고사리 } & \text { E } 60728 \\ \text { 큰설설고사리 } & \text { P } 150469 \\ \text { 사다리고사리 } & \text { A } 151550 \\ \text { 지네고사리 } & \text { I } 013219 \\ \text { 처녀고사리 } & \text { E } 71735\end{array}$

$\begin{array}{ccc}\text { 쇠고비 } & \text { P } 150606 & \text { I 등급종 } \\ \text { 산족제비고사리 } & \text { I } 059559 & \\ \text { 제주지네고사리 } & \text { I } 008238 & \text { IV 등급종 } \\ \text { 가는잎족제비고사리 } & \text { I } 013227 & \\ \text { 관중 } & \text { P } 150629 & \text { I 등급종 }\end{array}$


Appendix 1. Continued.

\begin{tabular}{|c|c|c|c|}
\hline Dryopteris erythrosora (D. C .Eaton) Kuntze & 홍지네고사리 & A 151283 & $\mathrm{I}$ 등급종 \\
\hline Dryopteris lacera (Thunb.) Kuntze & 비늘고사리 & A 053595 & \\
\hline Dryopteris monticola (Makino) C. Chr. & 왕지네고사리 & A 151212 & \\
\hline Dryopteris sacrosancta Koidz. & 애기족제비고사리 & I 008259 & \\
\hline Dryopteris saxifraga $\mathrm{H}$. Ito & 바위족제비고사리 & I 023213 & \\
\hline Dryopteris uniformis (Makino) Makino & 곰비늘고사리 & C 135312 & I 등급종 \\
\hline Polystichum polyblepharum (Roem. ex Kunze) C. Presl & 나도히초미 & P 150637 & \\
\hline Polystichum tripteron (Kunze) C. Presl & 십자고사리 & P 150632 & \\
\hline \multicolumn{4}{|l|}{ Davalliaceae 넉줄고사리과 } \\
\hline Davallia mariesii $\mathrm{T}$. Moore ex Baker & 넉줄고사리 & P 150629 & \\
\hline \multicolumn{4}{|l|}{ Polypodiaceae 고란초과 } \\
\hline Lepisorus thunbergianus (Kaulf.) Ching & 일엽초 & C 135366 & \\
\hline Lepisorus ussuriensis (Regel \& Maack) Ching & 산일엽초 & P 150029 & \\
\hline Pyrrosia linearifolia (Hook.) Ching & 우단일엽 & I 008265 & \\
\hline \multicolumn{4}{|l|}{ Pinaceae 소나무과 } \\
\hline Larix kaempferi (Lamb.) Carriere & 일본잎갈나무 & P 150320 & 식재 \\
\hline Pinus densiflora Siebold \& Zucc. & 소나무 & P 150686 & \\
\hline \multicolumn{4}{|l|}{ Cupressaceae 측백나무과 } \\
\hline Juniperus rigida Siebold \& Zucc. & 노간주나무 & E 90427 & \\
\hline \multicolumn{4}{|l|}{ Cephlaotaxaceae 개비자나무과 } \\
\hline Cephalotaxus harringtonia (Knight ex Forbes) K. Koch & 개비자나무 & P 150603 & I 등급종 \\
\hline \multicolumn{4}{|l|}{ Magnoliaceae 목련과 } \\
\hline Magnolia sieboldii K. Koch & 함박꽃나무 & P 150322 & \\
\hline \multicolumn{4}{|l|}{ Lauraceae 녹나무과 } \\
\hline Lindera erythrocarpa Makino & 비목나무 & I 008214 & \\
\hline Lindera glauca (Siebold \& Zucc.) Blume & 감태나무 & E 60762 & \\
\hline Lindera obtusiloba Blume & 생강나무 & E 60708 & \\
\hline Lindera sericea (Siebold \& Zucc.) Blume & 털조장나무 & I 013222 & IV 등급종 \\
\hline \multicolumn{4}{|l|}{ Chloranthaceae 홀아비꽃대과 } \\
\hline Chloranthus fortunei (A. Gray) Sloms & 옥녀꽃대 & Р 150834 & I 등급종 \\
\hline \multicolumn{4}{|l|}{ Saururaceae 삼백초과 } \\
\hline Houttuynia cordata Thunb. & 약모밀 & C 035434 & $\mathrm{~V}$ 등급종(재배) \\
\hline \multicolumn{4}{|l|}{ Aristolochiaceae 쥐방울덩굴과 } \\
\hline Asarum heterotropoides F. Schmidt & 털족도리풀 & 임형탁, 정수진. 010363 & \\
\hline Asarum sieboldii Miq. & 족도리풀 & P 150554 & \\
\hline \multicolumn{4}{|l|}{ Ranunculaceae 미나리아재비과 } \\
\hline Aconitum jaluense Kom. & 투구꽃 & A 011296 & I 등급종 \\
\hline Aconitum longecassidatum Nakai & 흰진범 & P 150562 & III 등급종 \\
\hline Actaea asiatica H. Hara & 노루삼 & А 011297 & \\
\hline Aquilegia buergeriana var. oxysepala (Trautv. \& Meyer) Kitam. & 매발톱 & 임형탁, 정수진 055360 & II 등급종 \\
\hline Caltha palustris $\mathrm{L}$. & 동의나물 & P 150502 & II 등급종 \\
\hline
\end{tabular}


Appendix 1. Continued.

\begin{tabular}{|c|c|c|c|}
\hline Cimicifuga foetida $\mathrm{L}$. & 황새승마 & C 035362 & \\
\hline Clematis apiifolia DC. & 사위질빵 & C 0651 & \\
\hline Clematis patens C. Morren \& Decne. & 큰꽃으아리 & A 011811 & I 등급종 \\
\hline Clematis terniflora DC. & 참으아리 & E 53003 & \\
\hline Hepatica asiatica Nakai & 노루귀 & A 151372 & \\
\hline Ranunculus cantoniensis DC. & 털개구리미나리 & P 150569 & \\
\hline Ranunculus chinensis Bunge & 젓가락나물 & E 71604 & \\
\hline Ranunculus japonicus Thunb. & 미나리아재비 & E 41503 & \\
\hline Ranunculus sceleratus L. & 개구리자리 & E 60706 & \\
\hline Semiaquilegia adoxoides (DC.) Makino & 개구리발톱 & A 151370 & I 등급종 \\
\hline Thalictrum actaefolium var. brevistylum Nakai & 은꿩 의다리 & C 135429 & 고유종 \\
\hline \multicolumn{4}{|l|}{ Berberidaceae 매자나무과 } \\
\hline Caulophyllum robustum Maxim. & 뀡의다리아재비 & A 151387 & II 등급종 \\
\hline \multicolumn{4}{|l|}{ Lardizabalaceae 으름덩굴과 } \\
\hline Akebia quinata (Houtt.) Decne. & 으름덩굴 & P 150328 & \\
\hline \multicolumn{4}{|l|}{ Menispermaceae 새모래덩굴과 } \\
\hline Cocculus trilobus (Thunb.) DC. & 댕댕이덩굴 & C 0582 & \\
\hline \multicolumn{4}{|l|}{ Sabiaceae 나도밤나무과 } \\
\hline Meliosma myriantha Siebold \& Zucc. & 나도밤나무 & I 008235 & I 등급종 \\
\hline Meliosma oldhamii Miq. ex Maxim. & 합다리나무 & P 150565 & I 등급종 \\
\hline \multicolumn{4}{|l|}{ Papaveraceae 양귀비과 } \\
\hline Chelidonium majus var. asiaticum (H. Hara) Ohwi & 애기똥풀 & E 53002 & \\
\hline Coreanomecon hylomeconoides Nakai & 매미꽃 & C 135030 & 고유종, IV 등급종 \\
\hline \multicolumn{4}{|l|}{ Fumaricaceae 현호색과 } \\
\hline Corydalis incisa (Thunb.) Pers. & 자주괴불주머니 & A 151302 & \\
\hline Corydalis remota Fisch. ex Maxim. & 현호색 & A 41501 & \\
\hline Corydalis speciosa Maxim. & 산괴불주머니 & E 41512 & \\
\hline \multicolumn{4}{|l|}{ Hamamelidaceae 조록나무과 } \\
\hline Corylopsis glabrescens var. gotoana (Makino) T. Yamanaka & 히어리 & C 135058 & IV 등급종 \\
\hline \multicolumn{4}{|l|}{ Ulmaceae 느릅나무과 } \\
\hline Aphananthe aspera (Thunb.) Planch. & 푸조나무 & I 010284 & I 등급종 \\
\hline Celtis jessoensis Koidz. & 풍게나무 & I 008229 & \\
\hline Celtis sinensis Pers. & 팽나무 & $\begin{array}{c}\text { T.Hoshino,H.T.Im \& } \\
\text { H.Ikeda 98060728 }\end{array}$ & \\
\hline Zelkova serrata (Thunb.) Makino & 느티나무 & E 71750 & \\
\hline \multicolumn{4}{|l|}{ Cannabinaceae 삼과 } \\
\hline Humulus japonicus Siebold \& Zucc. & 환삼덩굴 & E 90424 & \\
\hline \multicolumn{4}{|l|}{ Moraceae 뽛나무과 } \\
\hline Broussonetia kazinoki Siebold \& Zucc. & 닥나무 & A 010343 & \\
\hline Broussonetia kazinoki var. humilis Uyeki & 애기닥나무 & E 71605 & \\
\hline Broussonetia papyrifera (L.) L'Her. ex Vent. & 꾸지나무 & A 010345 & \\
\hline
\end{tabular}


Appendix 1. Continued.

\begin{tabular}{|c|c|c|c|}
\hline Morus bombycis Koidz. & 산뽕나무 & A 010347 & \\
\hline \multicolumn{4}{|l|}{ Urticaceae 쐐기풀과 } \\
\hline Boehmeria platanifolia Franch. \& Sav. & 개모시풀 & I 008224 & \\
\hline Boehmeria spicata (Thunb.) Thunb. & 좀깨잎나무 & A 010505 & \\
\hline Boehmeria tricuspis (Hance) Makino & 거북꼬리 & I 008256 & \\
\hline Laportea bulbifera (Siebold \& Zucc.) Wedd. & 혹쐐기풀 & I 008241 & \\
\hline Pilea japonica (Maxim.) Hand.-Mazz. & 산물통이 & C 0587 & \\
\hline Pilea mongolica Wedd. & 모시물통이 & I 013221 & \\
\hline Pilea peploides (Gaudich.) Hook. \& Arn. & 물통이 & A 010230 & \\
\hline Urtica thunbergiana Siebold \& Zucc. & 쐐기풀 & A 1154 & \\
\hline \multicolumn{4}{|l|}{ Juglandaceae 가래나무과 } \\
\hline Juglans mandshurica Maxim. & 가래나무 & A 010177 & $\mathrm{I}$ 등급종 \\
\hline Platycarya strobilacea Siebold \& Zucc. & 굴피나무 & E 81213 & \\
\hline \multicolumn{4}{|l|}{ Fagaceae 참나무과 } \\
\hline Quercus aliena Blume & 갈참나무 & E 71751 & \\
\hline Quercus dentata Thunb. & 떡갈나무 & A 151372 & \\
\hline Quercus mongolica Fisch. ex Ledeb. & 신갈나무 & E 71606 & \\
\hline Quercus serrata Murray & 졸참나무 & E 90410 & \\
\hline Quercus variabilis Blume & 굴참나무 & A 151377 & \\
\hline \multicolumn{4}{|l|}{ Betulaceae 자작나무과 } \\
\hline Alnus firma Siebold \& Zucc. & 사방오리 & E 50914 & \\
\hline Alnus hirsuta (Spach) Fisch. ex Rupr. & 물오리나무 & E 53005 & \\
\hline Alnus japonica (Thunb.) Steud. & 오리나무 & A 151281 & \\
\hline Carpinus cordata Blume & 까치박달 & E 102402 & \\
\hline Carpinus laxiflora (Siebold \& Zucc.) Blume & 서어나무 & E 102408 & \\
\hline Carpinus tschonoskii Maxim. & 개서어나무 & E 102410 & \\
\hline Corylus heterophylla Fisch. ex Trautv. & 개암나무 & Е 90434 & \\
\hline Corylus sieboldiana Blume & 참개암나무 & C 0582 & \\
\hline \multicolumn{4}{|l|}{ Phytolacaceae 자리공과 } \\
\hline Phytolacca americana L. & 미국자리공 & E 71608 & 외래식물 \\
\hline \multicolumn{4}{|l|}{ Chenopodiaceae 명아주과 } \\
\hline Chenopodium album var. centrorubrum Makino & 명아주 & E 71618 & \\
\hline Chenopodium ficifolium $\mathrm{Sm}$. & 좀명아주 & A 010393 & 외래식물 \\
\hline \multicolumn{4}{|l|}{ Amaranthaceae 비름과 } \\
\hline Achyranthes japonica (Miq.) Nakai & 쇠무릎 & C 0580 & \\
\hline \multicolumn{4}{|l|}{ Portulacaceae 쇠비름과 } \\
\hline Portulaca oleracea L. & 쇠비름 & P 150476 & \\
\hline \multicolumn{4}{|l|}{ Caryophyllaceae 석죽과 } \\
\hline Arenaria serpyllifolia $\mathrm{L}$. & 벼룩이자리 & E 60709 & \\
\hline Dianthus longicalyx Miq. & 술패랭이꽃 & A 1331 & \\
\hline Lychnis cognata Maxim. & 동자꽃 & E 71701 & I 등급종 \\
\hline
\end{tabular}


Appendix 1. Continued.

\begin{tabular}{|c|c|c|c|}
\hline Pseudostellaria heterophylla (Miq.) Pax & 개별꽃 & E 41501 & \\
\hline Pseudostellaria palibiniana (Takeda) Ohwi & 큰개별꽃 & C 135293 & \\
\hline Sagina japonica $($ Sw.) Ohwi & 개미자리 & A 055551 & \\
\hline Silene firma Siebold \& Zucc. & 장구채 & A 055516 & \\
\hline Stellaria alsine var. undulata (Thunb.) Ohwi & 벼룩나물 & A 151367 & \\
\hline Stellaria aquatica (L.) Scop. & 쇠별꽃 & P 150561 & \\
\hline Stellaria media (L.) Vill. & 별꽃 & C 5081 & \\
\hline \multicolumn{4}{|l|}{ Polygonaceae 마디풀과 } \\
\hline Fallopia ciliinervis (Nakai) K. Hammer & 나도하수오 & E 102404 & \\
\hline Fallopia dentatoalata (F. Schmidt) Holub & 큰닭의덩굴 & C 135402 & 외래식물 \\
\hline Polygonum aviculare $\mathrm{L}$. & 마디풀 & E 60702 & \\
\hline Polygonum dissitiflorum Hemsl. & 가시여뀌 & A 010379 & \\
\hline Polygonum filiforme Thunb. & 이삭여뀌 & C 135374 & \\
\hline Polygonum hydropiper L. & 여뀌 & A 010368 & \\
\hline Polygonum japonicum Meisn. & 흰꽃여뀌 & E 90431 & \\
\hline Polygonum lapathifolium $\mathrm{L}$. & 흰여뀌 & E 90429 & \\
\hline Polygonum lapathifolium $\mathrm{L}$. & 흰여뀌 & E 60701 & \\
\hline Polygonum longisetum Bruijn & 개여뀌 & E 90415 & \\
\hline Polygonum nepalense Meisn. & 산여뀌 & P 150629 & \\
\hline Polygonum perfoliatum (L.) L. & 며느리배꼽 & A 010378 & \\
\hline Polygonum posumbu Buch.-Ham. ex D. Don & 장대여뀌 & P 150635 & \\
\hline Polygonum sagittatum $\mathrm{L}$. & 미꾸리낚시 & Р 150596 & \\
\hline Polygonum senticosum (Meisn.) Franch. \& Sav. & 며느리밑씻개 & P 150590 & \\
\hline Polygonum thunbergii Siebold \& Zucc. & 고마리 & C 135405 & \\
\hline Rumex acetosa $\mathrm{L}$. & 수영 & E 60756 & \\
\hline Rumex crispus $\mathrm{L}$. & 소리쟁이 & A 010385 & 외래식물 \\
\hline \multicolumn{4}{|l|}{ Theaceae 차나무과 } \\
\hline Camellia sinensis (L.) Kuntze & 차나무 & C 135365 & \\
\hline Stewartia koreana Nakai ex Rehder & 노각나무 & E 71752 & 고유종, III 등급종 \\
\hline \multicolumn{4}{|l|}{ Actinidiaceae 다래나무과 } \\
\hline Actinidia arguta (Siebold \& Zucc.) Planch. ex Miq. & 다래 & E 53032 & \\
\hline Actinidia polygama (Siebold \& Zucc.) Maxim. & 개다래 & E 53033 & \\
\hline \multicolumn{4}{|l|}{ Guttiferae 물레나물과 } \\
\hline Hypericum ascyron $\mathrm{L}$. & 물레나물 & P 150632 & \\
\hline Hypericum erectum Thunb. & 고추나물 & A 011140 & \\
\hline Hypericum laxum (Blume) Koidz. & 좀고추나물 & E 71677 & \\
\hline \multicolumn{4}{|l|}{ Tiliaceae 피나무과 } \\
\hline Corchoropsis tomentosa (Thunb.) Makino & 수까치깨 & C 135361 & \\
\hline Grewia parviflora Bunge & 장구밤나무 & A 151368 & I 등급종 \\
\hline \multicolumn{4}{|l|}{ Malvaceae 아욱과 } \\
\hline Hibiscus syriacus L. & 무궁화 & C 135404 & \\
\hline
\end{tabular}


Appendix 1. Continued.

\section{Flacourtiaceae 산유자나무과}

Idesia polycarpa Maxim.

Violaceae 제비꽃과

Viola acuminata Ledeb.

Viola albida Palib.

Viola albida var. chaerophylloides (Regel) F. Maek.

Viola aponica Langsd. ex Ging.

Viola collina Besser

Viola hondoensis W. Becker \& H. Boissieu

Viola keiskei Miq.

Viola lactiflora Nakai

Viola mandshurica W. Becker

Viola orientalis (Maxim.) W. Becker

Viola rossii Hemsl.

Viola tokubuchiana var. takedana (Makino) F. Maek.

Viola verecunda A. Gray

Viola yedoensis Makino

\section{Cucurbitaceae 박과}

Melothria japonica (Thunb.) Maxim. ex Cogn.

\section{Salicaceae 버드나무과}

Salix caprea $\mathrm{L}$.

Salix chaenomeloides Kimura

Salix gilgiana Seemen

Salix graciliglans Nakai

Salix gracilistyla Miq.

Salix hallaisanensis H. Lev.

Salix koreensis Andersson

Salix koriyanagi Kimura ex Goerz

Salix purpurea var. smithiana Trauty.

\section{Cruciferae 십자화과}

Arabis glabra (L.) Bernh.

Arabis hirsuta (L.) Scop.

Capsella bursa-pastoris (L.) Medik.

Cardamine fallax (O. E. Schulz) Nakai

Cardamine flexuosa With.

Cardamine impatiens L.

Cardamine leucantha (Tausch) O. E. Schulz

Draba nemorosa for. leiocarpa (Lindb.) Kitag.

Draba nemorosa L.

Lepidium vvirginicum $\mathrm{L}$.

$$
\text { 이나무 }
$$

I 013208

III 등급종

\section{졸방제비꽃}

태백제비꽃

남산제비꽃

왜제비꽃

둥근털제비꽃

아욱제비꽃

잔털제비꽃

흰젓제비꽃

제비꽃

노랑제비꽃

고깔제비꽃

민둥뫼제비꽃

콩제비꽃

호제비꽃

새박

호랑버들

왕버들

내버들

눈갯버들

갯버들

떡버들

버드나무

키버들

당키버들

장대나물

털장대

냉이

좁쌀냉이

황새냉이

싸리냉이

미나리냉이

민꽃다지

꽃다지

콩다닥냉이

A 011182

P 150619

P 150567

P 150640

E 53034

A 011170

A 011159

A 055276

C 0503

P 150555

II 등급종

A 011181

P 150553

II 등급종

A 011185

E 41541

Hong.H.H\&Lee.D.W. 011369

II 등급종

P 150488

A 054773

I 등급종

임형탁. 정수진. 055543

E 41505

E 41510

임형탁, 정수진. 054774

고유종

P 150481

A 054770

P 150498

III 등급종

E 60761

P 150570

E 41505

E 41507

C 135419

A 011206

E 41519

E 41506

E 41507

E 60723
외래식물 
Appendix 1. Continued.

Rorippa indica (L.) Hiern

Rorippa palustris (L.) Besser

\section{Ericaceae 진달래과}

Rhododendron mucronulatum var. ciliatum Nakai

Rhododendron schlippenbachii Maxim.

Vaccinium hirtum var. koreanum (Nakai) Kitam.

Vaccinium oldhamii Miq.

\section{Pyrolacae 노루발과}

Chimaphila japonica Miq.

Pyrola japonica Klenze ex Alef.

Monotropaceae 수정난풀과

Monotropa uniflora L.

\section{Ebenaceae 감나무과}

Diospyros lotus L.

\section{Styracaceae 때죽나무과}

Styrax japonicus Siebold \& Zucc.

Styrax obassia Siebold \& Zucc.

\section{Symplicaceae 노린재나무과}

Symplocos sawafutagi Nagam.

Symplocos tanakana Nakai

\section{Primulaceae 앵초과}

Androsace umbellata (Lour.) Merr.

Lysimachia clethroides Duby

Lysimachia japonica Thunb.

Primula sieboldii E. Morren

\section{Hydrangeaceae 수국과}

Deutzia parviflora Bunge

Deutzia uniflora Shirai

Hydrangea serrata for. acuminata (Siebold \& Zucc.) E. H. Wilson

Philadelphus pekinensis Rupr.

\section{Crassulaceae 돌나물과}

Sedum aizoon $\mathrm{L}$.

Sedum bulbiferum Makino

Sedum kamtschaticum Fisch. \& C. A. Mey.

Sedum polytrichoides Hemsl.

Sedum sarmentosum Bunge

Saxifragaceae 범의귀과

Astilbe rubra Hook. f. \& Thomson ex Hook. f.

Chrysosplenium flagelliferum $\mathrm{F}$. Schmidt

Chrysosplenium macrostemon (A. Terracc.) H. Hara

개갓냉이

P 150592

A 011201

$\begin{array}{cc}\text { 털진달래 } & \text { A } 010010 \\ \text { 철쭉 } & \text { A } 010115 \\ \text { 산앵도나무 } & \text { P } 150563 \\ \text { 정금나무 } & \text { C } 135067\end{array}$

E 71643

매화노루발

A 041761

노루발

I 013205

수정난풀

E 453016

고욤나무

C 134740

때죽나무

C 0585

쪽동백나무

A 010028

노린재나무

P 150556

검노린재

E 41517

봄맞이

A 010066

큰까치수염

C 135322

좀가지풀

P 150466

말발도리 P 150533

매화말발도리

A 010126

산수국

A 010243

애기고광나무

E 53007
II 등급종

III 등급종

고유종, II 등급종

I 등급종

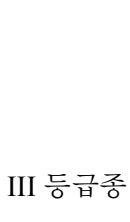


Appendix 1. Continued.

\begin{tabular}{|c|c|c|c|}
\hline Saxifraga fortunei var. incisolobata (Engl. \& Irmsch.) Nakai & 바위떡풀 & C 135334 & \\
\hline \multicolumn{4}{|l|}{ Rosaceae 장미과 } \\
\hline Agrimonia pilosa Ledeb. & 짚신나물 & A 011200 & \\
\hline Duchesnea chrysantha (Zoll. \& Moritzi) Miq. & 뱀딸기 & C 135369 & \\
\hline Geum aleppicum Jacq. & 큰뱀무 & $\begin{array}{l}\text { T.Hoshino,H.T.Im \& } \\
\text { H.Ikeda 98060714 }\end{array}$ & \\
\hline Geum japonicum Thunb. & 뱀무 & C 135367 & \\
\hline Malus sieboldii (Regel) Rehder & 아그배나무 & P 150471 & \\
\hline Potentilla amurensis Maxim. & 좀개소시랑개비 & А 011209 & 외래식물 \\
\hline Potentilla anemonifolia Lehm. & 가락지나물 & A 011212 & \\
\hline Potentilla dickinsii Franch. \& Sav. & 돌양지꽃 & C 135393 & II등급종 \\
\hline Potentilla dickinsii var. breviseta Nakai & 참양지꽃 & E 71708 & 고유종 \\
\hline Potentilla fragarioides $\mathrm{L}$. & 양지꽃 & A 011205 & \\
\hline Potentilla freyniana Bornm. & 세잎양지꽃 & A 011207 & \\
\hline Potentilla yokusaiana (H. Lev.) Nakai & 민눈양지꽃 & C 0584 & \\
\hline Prunus jamasakura Siebold ex Koidz. & 벚나무 & A 011231 & \\
\hline Prunus verecunda (Koidz.) Koehne & 개벚나무 & E 41512 & \\
\hline Rosa maximowicziana Regel & 용가시나무 & Р 150477 & \\
\hline Rosa multiflora Thunb. & 찔레꽃 & C 135082 & \\
\hline Rubus corchorifolius L. f. & 수리딸기 & A 011213 & \\
\hline Rubus coreanus Miq. & 복분자딸기 & A 011216 & \\
\hline Rubus crataegifolius Bunge & 산딸기 & Р 150474 & \\
\hline Rubus oldhamii Miq. & 줄딸기 & Р 150493 & \\
\hline Rubus parvifolius $\mathrm{L}$. & 멍석딸기 & E 71614 & \\
\hline Sanguisorba officinalis L. & 오이풀 & A 011199 & \\
\hline Spiraea prunifolia var. simpliciflora (Nakai) Nakai & 조팝나무 & E 41418 & \\
\hline Stephanandra incisa (Thunb.) Zabel & 국수나무 & E 50915 & \\
\hline \multicolumn{4}{|l|}{ Leguminosae 콩과 } \\
\hline Aeschynomene indica $\mathrm{L}$. & 자귀풀 & E 90414 & \\
\hline Albizia julibrissin Durazz. & 자귀나무 & C 135437 & \\
\hline Amorpha fruticosa $\mathrm{L}$. & 족제비싸리 & P 150578 & 외래식물 \\
\hline Astragalus sinicus $\mathrm{L}$. & 자운영 & A 71624 & 외래식물 \\
\hline Caragana sinica (Buc'hoz) Rehder & 골담초 & 임형탁, 정수진 010269 & \\
\hline Chamaecrista nomame (Siebold) H. Ohashi & 차풀 & E 71709 & \\
\hline Desmodium oldhamii Oliv. & 큰도둑놈의갈고리 & E 71625 & \\
\hline Desmodium podocarpum subsp. oxyphyllum Maxim. & 도둑놈의갈고리 & I 008233 & \\
\hline Dunbaria villosa (Thunb.) Makino & 여우팥 & A 1934 & \\
\hline Glycine soja Siebold \& Zucc. & 돌콩 & C 0579 & \\
\hline Indigofera koreana Ohwi & 민땅비싸리 & P 150507 & 고유종 \\
\hline Kummerowia stipulacea (Maxim.) Makino & 둥근매듭풀 & P 150571 & \\
\hline Kummerowia striata (Thunb.) Schindl. & 매듭풀 & Р 150604 & \\
\hline
\end{tabular}


Appendix 1. Continued.

\begin{tabular}{|c|c|c|c|}
\hline Lespedeza bicolor Turcz. & 싸리 & A 1878 & \\
\hline Lespedeza cuneata (Dum. Cours.) G. Don. & 비수리 & E 90434 & \\
\hline Lespedeza cyrtobotrya Miq. & 참싸리 & C 0606 & \\
\hline Lespedeza maximowiczii C. K. Schneid. & 조록싸리 & A 010268 & \\
\hline Lespedeza thunbergii subsp. formosa (Vogel) H. Ohashi & 풀싸리 & C 0581 & \\
\hline Maackia amurensis Rupr. \& Maxim. & 다릅나무 & E 71617 & \\
\hline Maackia amurensis var. buergeri (Maxim.) C. K. Schneid. & 개물푸레나무 & E 53008 & \\
\hline Rhynchosia acuminatifolia Makino & 큰여우콩 & E 90433 & III 등급종 \\
\hline Vicia dasycarpa Ten. & 각시갈퀴나물 & C 134732 & 외래식물 \\
\hline Vicia hirticalycina Nakai & 나래완두 & P 150565 & 고유종 \\
\hline Vicia unijuga $\mathrm{A}$. Braun & 나비나물 & A 010274 & \\
\hline \multicolumn{4}{|l|}{ Elaeagnacea 보리수나무과 } \\
\hline Elaeagnus umbellata Thunb. & 보리수나무 & P 150571 & \\
\hline \multicolumn{4}{|l|}{ Onagaceae 바늘꽃과 } \\
\hline $\begin{array}{l}\text { Circaea lutetiana subsp. quadrisulcata (Maxim.) Asch. \& } \\
\text { Magnus }\end{array}$ & 말털이슬 & A 011124 & I 등급종 \\
\hline Circaea mollis Siebold \& Zucc. & 털이슬 & I 008243 & \\
\hline Epilobium pyrricholophum Franch. \& Sav. & 바늘꽃 & A 011126 & \\
\hline Ludwigia epilobioides Maxim. & 여뀌바늘 & E 90413 & \\
\hline Oenothera glazioviana Micheli & 큰달맞이꽃 & C 0606 & 외래식물 \\
\hline Oenothera odorata Jacq. & 달맞이꽃 & C 134994 & 외래식물 \\
\hline \multicolumn{4}{|l|}{ Alangiaceae 박쥐나무과 } \\
\hline Alangium platanifolium var. trilobum (Miq.) Ohwi & 박쥐나무 & E 71718 & \\
\hline \multicolumn{4}{|l|}{ Cornaceae 충충나무과 } \\
\hline Cornus controversa Hemsl. & 층층나무 & E 90418 & \\
\hline Cornus kousa F. Buerger ex Miq. & 산딸나무 & C 135400 & \\
\hline \multicolumn{4}{|l|}{ Celastraceae 노박덩굴과 } \\
\hline Celastrus orbiculatus Thunb. & 노박덩굴 & Р 150841 & \\
\hline Euonymus alatus for. cilatodentatus Hiyama & 회잎나무 & E 71633 & \\
\hline Euonymus maackii Rupr. & 좁은잎참빗살나무 & 정정채 050172 & II 등급종 \\
\hline Euonymus oxyphyllus Miq. & 참회나무 & E 71634 & \\
\hline Tripterygium regelii Sprague \& Takeda & 미역줄나무 & A 010340 & \\
\hline \multicolumn{4}{|l|}{ Aquifoliaceae 감탕나무과 } \\
\hline Ilex macropoda for. pseudomacropoda (Loes.) H. Hara & 민대팻집나무 & C 134976 & \\
\hline \multicolumn{4}{|l|}{ Euphorbiaceae 대극과 } \\
\hline Euphorbia sieboldiana C. Morren \& Decne. & 개감수 & C 135314 & \\
\hline Neoshirakia japonica (Siebold \& Zucc.) Esser & 사람주나무 & C 135109 & \\
\hline Securinega suffruticosa (Pall.) Rehder & 광대싸리 & C 135232 & \\
\hline \multicolumn{4}{|l|}{ Rhamnanceae 갈매나무과 } \\
\hline Rhamnella franguloides (Maxim.) Weberb. & 까마귀베개 & C 5090 & \\
\hline Rhamnus yoshinoi Makino & 짝자래나무 & P 150560 & \\
\hline
\end{tabular}


Appendix 1. Continued.

\section{Vitaceae 포도과}

Ampelopsis brevipedunculata (Maxim.) Trautv.

Vitis flexuosa Thunb.

Staphyleaceae 고추나무과

Euscaphis japonica (Thunb.) Kanitz

Staphylea bumalda DC.

\section{Aceraceae 단풍나무과}

Acer palmatum Thunb.

Acer pictum var. mono (Maxim.) Franch.

Acer pseudosieboldianum (Pax) Kom.

Acer tataricum subsp. ginnala (Maxim.) Wesm.

\section{Anacardiaceae 옻나무과}

Toxicodendron trichocarpum (Miq.) Kuntze

Simaroubaceae 소태나무과

Picrasma quassioides (D. Don) Benn.

\section{Rutaceae 운향과}

Orixa japonica Thunb.

Zanthoxylum piperitum DC.

Zanthoxylum schinifolium Siebold \& Zucc.

\section{Oxalidaceae 갱이밥과}

Oxalis corniculata L.

\section{Geraniaceae 쥐손이풀과}

Geranium thunbergii Siebold ex Lindl. \& Paxton

Geranium wilfordii Maxim.

\section{Balsaminaceae 봉선화과}

Impatiens nolitangere $\mathrm{L}$.

Impatiens textori Miq.

Impatiens textori var. koreana Nakai

\section{Araliaceae 두릅나무과}

Aralia elata (Miq.) Seem.

Eleutherococcus sessiliflorus (Rupr. \& Maxim.) S. Y. Hu

\section{Umbeliferae 미나리과}

Angelica decursiva (Miq.) Franch. \& Sav.

Angelica polymorpha Maxim.

Bupleurum falcatum L.

Cryptotaenia japonica Hassk.

Cymopterus melanotilingia (H. Boissieu) C. Y. Yoon

Hydrocotyle maritima Honda

Hydrocotyle ramiflora Maxim.

Osmorhiza aristata (Thunb.) Rydb.

Ostericum grosseserratum (Maxim.) Kitag.

\begin{tabular}{|c|c|c|}
\hline 개머루 & Е 71626 & \\
\hline 새머루 & E 53010 & \\
\hline 말오줌때 & E 71628 & I 등급종 \\
\hline 고추나무 & C 135178 & \\
\hline 단풍나무 & E 41515 & III 등급종 \\
\hline 고로쇠나무 & C 134744 & \\
\hline 당단풍나무 & C 0514 & \\
\hline 신나무 & P 150492 & \\
\hline 개옻나무 & C 135088 & \\
\hline 소태나무 & P 150332 & \\
\hline 상산 & C 5091 & I 등급종 \\
\hline 초피나무 & E 71749 & \\
\hline 산초나무 & C 135372 & \\
\hline 괭이밥 & C 135357 & \\
\hline 이질풀 & Е 81214 & \\
\hline 세잎쥐손이 & P 150479 & \\
\hline 노랑물봉선 & С 0603 & I 등급종 \\
\hline 물봉선 & C 0530 & \\
\hline 흰물봉선 & C 135398 & \\
\hline 두릅나무 & C 5083 & \\
\hline 오갈피나무 & E 71639 & I 등급종 \\
\hline
\end{tabular}

\begin{tabular}{|c|c|c|}
\hline 바디나물 & E 102412 & \\
\hline 궁궁이 & P 150343 & \\
\hline 시호 & P 150548 & \\
\hline 파드득나물 & E 71642 & \\
\hline 큰참나물 & A 011287 & II 등급종 \\
\hline 선피막이 & E 53014 & \\
\hline 큰피막이 & A 2303 & \\
\hline 긴사상자 & E 71720 & \\
\hline 신감채 & E 102413 & \\
\hline
\end{tabular}


Appendix 1. Continued.

\begin{tabular}{|c|c|c|c|}
\hline Ostericum sieboldii (Miq.) Nakai & 묏미나리 & C 135267 & \\
\hline Pimpinella brachycarpa (Kom.) Nakai & 참나물 & A 011290 & \\
\hline Sanicula chinensis Bunge & 참반디 & A 011275 & \\
\hline Sanicula tuberculata Maxim. & 애기참반디 & E 53013 & III 등급종 \\
\hline Sium ninsi L. & 감자개발나물 & A 011280 & \\
\hline Sium suave Walter & 개발나물 & C 0502 & \\
\hline Torilis japonica (Houtt.) DC. & 사상자 & A 011270 & \\
\hline \multicolumn{4}{|l|}{ Gentianaceae 용담과 } \\
\hline Swertia pseudochensis H. Hara & 자주쓴풀 & Р 150469 & \\
\hline Swertia scabra Bunge & 용담 & A 045119 & \\
\hline Swertia zollgeri Fawc. & 큰구슬붕이 & A 045220 & \\
\hline \multicolumn{4}{|l|}{ Apocynaceae 협죽도과 } \\
\hline Trachelospermum asiaticum (Siebold \& Zucc.) Nakai & 마삭줄 & P 150566 & \\
\hline \multicolumn{4}{|l|}{ Asclepiadaceae 박주가리과 } \\
\hline Cynanchum ascyrifolium (Franch. \& Sav.) Matsum. & 민백미꽃 & Р 150504 & \\
\hline Metaplexis japonica (Thunb.) Makino & 박주가리 & E 90423 & \\
\hline \multicolumn{4}{|l|}{ Solanaceae 가지과 } \\
\hline Physaliastrum echatum (Yatabe) Makino & 가시꽈리 & P 150586 & \\
\hline Solanum lyratum Thunb. & 배풍등 & C 0593 & \\
\hline Solanum nigrum $\mathrm{L}$. & 까마중 & E 71646 & \\
\hline \multicolumn{4}{|l|}{ Convolvulaceae 메꽃과 } \\
\hline Calystegia hederacea (Thunb.) Makino & 애기메꽃 & E 71635 & \\
\hline Cuscuta australis R. Br. & 실새삼 & A 010042 & \\
\hline \multicolumn{4}{|l|}{ Borraginaceae 지치과 } \\
\hline Bothriospermum tenellum (Hornem.) Fisch. \& C. A. Mey. & 꽃받이 & E 71636 & \\
\hline Trigonotis peduncularis (Trevis.) Benth. ex Baker \& S. Moore & 꽃마리 & E 41516 & \\
\hline Trigonotis radicans var. sericea Thunb. & 참꽃마리 & A 010055 & \\
\hline \multicolumn{4}{|l|}{ Verbenaceae 마편초과 } \\
\hline Callicarpa japonica Thunb. & 작살나무 & C 135403 & \\
\hline Clerodendrum trichotomum Thunb. & 누리장나무 & E 71716 & \\
\hline \multicolumn{4}{|l|}{ Phrymaceae 파리풀과 } \\
\hline Phryma leptostachya var. oblongifolia (Koidz.) Honda & 파리풀 & C 135156 & \\
\hline \multicolumn{4}{|l|}{ Labiatae 꿀풀과 } \\
\hline Agastache rugosa (Fisch. \& C. A. Mey.) Kuntze & 배초향 & P 150480 & \\
\hline Ajuga decumbens Thunb. & 금창초 & A 012612 & \\
\hline Clinopodium chinense var. parviflorum (Kudo) H. Hara & 층층이꽃 & C 135431 & \\
\hline Clinopodium micranthum (Regel) H. Hara & 두메층층이 & C 135376 & $\mathrm{I}$ 등급종 \\
\hline Elsholtzia ciliata (Thunb.) H. Hyl. & 향유 & P 150612 & \\
\hline Elsholtzia splendens Nakai ex F. Maek. & 꽃향유 & P 150481 & \\
\hline Isodon inflexus (Thunb.) Kudo & 산박하 & A 012628 & \\
\hline Lamium album var. barbatum (Siebold \& Zucc.) Franch. \& Sav. & 광대수염 & P 150568 & \\
\hline
\end{tabular}


Appendix 1. Continued.

\begin{tabular}{|c|c|c|c|}
\hline Lycopus lucidus Turcz. ex Benth. & 쉽싸리 & A 012650 & \\
\hline Lycopus maackianus Makino & 애기쉽싸리 & A 012652 & $\mathrm{I}$ 등급종 \\
\hline Meehania urticifolia (Miq.) Makino & 벌깨덩굴 & E 50904 & \\
\hline Mosla dianthera (Buch.-Ham. ex Roxb.) Maxim. & 쥐깨풀 & P 150488 & \\
\hline Mosla punctulata (J. F. Gmel.) Nakai & 들깨풀 & Р 150594 & \\
\hline Prunella asiatica Nakai & 꿀풀 & E 60717 & \\
\hline Salvia japonica Thunb. & 둥근배암차즈기 & P 150561 & III 등급종 \\
\hline Scutellaria insignis Nakai & 광릉골무꽃 & E 53018 & 고유종, III 등급종 \\
\hline Scutellaria pekensis var. transitra (Makino) H. Hara ex H. W. Li & 산골무꽃 & A 0628008 & \\
\hline Scutellaria pekensis var. ussuriensis (Regel) Hand.-Mazz. & 호골무꽃 & A 9807999 & \\
\hline \multicolumn{4}{|l|}{ Plantaginaceae 질경이과 } \\
\hline Plantago asiatica $\mathrm{L}$. & 질경이 & P 150591 & \\
\hline \multicolumn{4}{|l|}{ Oleaceae 물푸레나무과 } \\
\hline Forsythia koreana (Rehder) Nakai & 개나리 & 임형탁, 정수진 010093 & 고유종 \\
\hline Fraxinus rhynchophylla Hance & 물푸레나무 & E 50903 & \\
\hline Fraxinus sieboldiana Blume & 쇠물푸레나무 & C 0619 & \\
\hline Ligustrum obtusifolium Siebold \& Zucc. & 쥐똥나무 & E 90413 & \\
\hline \multicolumn{4}{|l|}{ Scrophulariaceae 현삼과 } \\
\hline Mazus pumilus (Burm. f.) Steenis & 주름잎 & E 71647 & \\
\hline Melampyrum roseum Maxim. & 꽃며느리밥풀 & E 71728 & \\
\hline Melampyrum roseum var. japonicum Franch. \& Sav. & 수염며느리밥풀 & A 055402 & \\
\hline Pedicularis resupinata $\mathrm{L}$. & 송이풀 & А 055399 & \\
\hline Phtheirospermum japonicum (Thunb.) Kanitz & 나도송이풀 & C 0501 & \\
\hline Scutellaria dentata var. alpina Nakai & 수골무꽃 & P 150562 & \\
\hline Veronica arvensis $\mathrm{L}$. & 선개불알풀 & A 055403 & 외래식물 \\
\hline Veronica hederaefolia $\mathrm{L}$. & 눈개불알풀 & C 135307 & 외래식물 \\
\hline Veronica persica Poir. & 큰개불알풀 & C 5079 & 외래식물 \\
\hline \multicolumn{4}{|l|}{ Acanthaceae 쥐꼬리망초과 } \\
\hline Justicia procumbens L. & 쥐꼬리망초 & I 008212 & \\
\hline \multicolumn{4}{|l|}{ Campanulaceae 초롱꽃과 } \\
\hline Adenophora divaricata Franch. \& Sav. & 넓은잔대 & E 102424 & \\
\hline Adenophora palustris Kom. & 진퍼리잔대 & C 172167 & $\begin{array}{c}\mathrm{V} \text { 등급종, } \\
\text { 적색목록(위기 }[\mathrm{EN}])\end{array}$ \\
\hline Adenophora remotiflora (Siebold \& Zucc.) Miq. & 모시대 & C 135385 & \\
\hline Adenophora triphylla var japonica (Regel) H. Hara & 잔대 & C 0475 & \\
\hline Adenophora verticillata var. hirsuta for. Schmidt & 털잔대 & Р 150491 & \\
\hline Asyneuma japonicum (Miq.) Briq. & 영아자 & $\begin{array}{l}\text { Hong.H.H\&Lee.D.W. } \\
011531\end{array}$ & \\
\hline Codonopsis lanceolata (Siebold \& Zucc.) Trautv. & 더덕 & E 71652 & \\
\hline Lobelia chinensis Lour. & 수염가래꽃 & A 055246 & \\
\hline Lobelia sessilifolia Lamb. & 숫잔대 & A 055245 & II 등급종 \\
\hline
\end{tabular}


Appendix 1. Continued.

\begin{tabular}{|c|c|c|c|}
\hline Platycodon grandiflorum (Jacq.) A. DC. & 도라지 & C 0652 & \\
\hline \multicolumn{4}{|l|}{ Rubiaceae 꼭두서니과 } \\
\hline Asperula maximowiczii Kom. & 개갈퀴 & C 0583 & \\
\hline Galium dahuricum Turcz. & 큰잎갈퀴 & C 135263 & \\
\hline Galium gracilens (A. Gray) Makino & 좀네잎갈퀴 & P 150563 & \\
\hline Galium pogonanthum (Wallr.) Hayek & 산갈퀴 & A 055463 & \\
\hline Galium verum var. asiaticum Nakai & 솔나물 & Р 150344 & \\
\hline Paederia scandens (Lour.) Merr. & 계요등 & E 71649 & \\
\hline Rubia akane Nakai & 꼭두서니 & C 0516 & \\
\hline Rubia chinensis Regel \& Maack & 큰꼭두서니 & E 71729 & \\
\hline Rubia cordifolia var. pratensis Maxim. & 갈퀴꼭두서니 & P 150568 & \\
\hline \multicolumn{4}{|l|}{ Diervillaceae 병꽃나무과 } \\
\hline Weigela subsessilis (Nakai) L. H. Bailey & 병꽃나무 & E 71651 & 고유종 \\
\hline \multicolumn{4}{|l|}{ Caprifoliaceae 인동과 } \\
\hline Lonicera harai Makino & 길마가지나무 & Р 150339 & \\
\hline Lonicera japonica Thunb. & 인동덩굴 & E 53020 & \\
\hline \multicolumn{4}{|l|}{ Viburnaceae 산분꽃나무과 } \\
\hline Viburnum dilatatum Thunb. & 가막살나무 & E 53019 & \\
\hline Viburnum erosum Thunb. & 덜뀡나무 & C 135225 & \\
\hline Viburnum wrightii Miq. & 산가막살나무 & E 71731 & \\
\hline \multicolumn{4}{|l|}{ Adoxaceae 연복초과 } \\
\hline Adoxa moschatella $\mathrm{L}$. & 연복초 & A 011240 & II 등급종 \\
\hline Sambucus racemosa subsp. sieboldiana (Miq.) H. Hara & 딱총나무 & E 71748 & \\
\hline \multicolumn{4}{|l|}{ Valerianaceae 마타리과 } \\
\hline Patrinia scabiosifolia Fisch. ex Trevir. & 마타리 & C 135344 & \\
\hline Patrinia villosa (Thunb.) Juss. & 뚝갈 & P 150491 & \\
\hline Valeriana fauriei Briq. & 쥐오줌풀 & E 50905 & \\
\hline \multicolumn{4}{|l|}{ Compositae 국화과 } \\
\hline Adenocaulon himalaicum Edgew. & 멸가치 & I 008251 & \\
\hline Ainsliaea acerifolia Sch. Bip. & 단풍취 & A 010079 & \\
\hline Ainsliaea apiculata Sch. Bip. Ex Zoll. & 좀딱취 & I 008264 & II 등급종 \\
\hline Ambrosia artemisiifolia $\mathrm{L}$. & 돼지풀 & C 135436 & 생태계교란생물 \\
\hline Artemisia japonica Thunb. & 제비쑥 & C 0592 & \\
\hline Artemisia keiskeana Miq. & 맑은대쑥 & E 102442 & \\
\hline Artemisia princeps Pamp. & 쑥 & E 90426 & \\
\hline Artemisia stolonifera (Maxim.) Kom. & 넓은잎외잎쑥 & A 010083 & \\
\hline Aster ageratoides Turcz. & 까실쑥부쟁이 & E 102427 & \\
\hline Aster koraiensis Nakai & 벌개미취 & A 042803 & 고유종 \\
\hline Aster scaber Thunb. & 참취 & E 71731 & \\
\hline Aster yomena (Kitam.) Honda & 쑥부쟁이 & E 71657 & \\
\hline Atractylodes ovata (Thunb.) DC. & 삽주 & C 134987 & \\
\hline
\end{tabular}


Appendix 1. Continued.

\begin{tabular}{|c|c|c|c|}
\hline Bidens frondosa $\mathrm{L}$. & 미국가막사리 & E 71659 & 외래식물 \\
\hline Carpesium abrotanoides $\mathrm{L}$. & 담배풀 & E 81217 & \\
\hline Cirsium japonicum var. ussuriense (Regel) Kitam. & 엉겅퀴 & A 3067 & \\
\hline Cirsium setidens (Dunn) Nakai & 고려엉겅퀴 & E 102430 & 고유종, II 등급종 \\
\hline Conyza canadensis (L.) Cronquist & 망초 & E 90418 & 외래식물 \\
\hline Crassocephalum crepidioides (Benth.) S. Moore & 주홍서나물 & C 0574 & 외래식물 \\
\hline Crepidiastrum denticulatum (Houtt.) J. H. Pak \& Kawano & 이고들빼기 & A 010026 & \\
\hline Crepidiastrum sonchifolium (Bunge) J. H. Pak \& Kawano & 고들빼기 & E 60719 & \\
\hline Dendranthema boreale (Makino) Ling & 산국 & E 90412 & \\
\hline Dendranthema zawadskii var. latilobum (Maxim.) Kitam. & 구절초 & P 150596 & \\
\hline Eclipta prostrata (L.) L. & 한련초 & E 90420 & \\
\hline Erigeron annuus (L.) Pers. & 개망초 & E 71658 & 외래식물 \\
\hline Euchiton japonicus (Thunb.) Holub & 풀솜나물 & P 150493 & \\
\hline Eupatorium japonicum Thunb. & 등골나물 & E 81218 & \\
\hline Eupatorium lindleyanum DC. & 골등골나물 & E 102425 & \\
\hline Galinsoga quadriradiata Ruiz \& Pav. & 털별꽃아재비 & I 013224 & 외래식물 \\
\hline Hemistepta lyrata Bunge & 지칭개 & P 150569 & \\
\hline Hieracium umbellata $\mathrm{L}$. & 조밥나물 & P 150485 & \\
\hline Inula britannica var. lineariifolia (Turcz.) Regel & 가는금불초 & P 150588 & \\
\hline Ixeridium dentatum (Thunb.) Tzvelev & 씀바귀 & E 71660 & \\
\hline Lactuca indica var. laciniata (Houtt.) H. Hara & 왕고들빼기 & E 90425 & \\
\hline Lactuca raddeana Maxim. & 산씀바귀 & P 150591 & \\
\hline Ligularia fischeri (Ledeb.) Turcz. & 곰취 & A 010021 & II 등급종 \\
\hline Petasites japonicus (Siebold \& Zucc.) Maxim. & 머위 & C 135291 & \\
\hline Pseudognaphalium affine (D. Don) Anderb. & 떡쑥 & E 71655 & \\
\hline Saussurea gracilis Maxim. & 은분취 & E 102431 & \\
\hline Saussurea macrolepis (Nakai) Kitam. & 각시서덜취 & E 102432 & 고유종, II 등급종 \\
\hline Saussurea maximowiczii Herder & 버들분취 & A 010016 & \\
\hline Serratula coronata subsp. insularis (Iljin) Kitam. & 산비장이 & P 150384 & \\
\hline Sigesbeckia glabrescens Makino & 진득찰 & E 90428 & \\
\hline Sigesbeckia pubescens Makino & 털진득찰 & P 150579 & \\
\hline Solidago virgaurea subsp. asiatica Kitam. ex H. Hara & 미역취 & C 135360 & \\
\hline Syneilesis palmata (Thunb.) Maxim. & 우산나물 & A 010025 & \\
\hline Synurus deltoides (Aiton) Nakai & 수리취 & E 41522 & \\
\hline Youngia japonica (L.) DC. & 뽀리뱅이 & C 135061 & \\
\hline \multicolumn{4}{|l|}{ Araceae 천남성과 } \\
\hline Arisaema amurense Maxim. & 둥근잎천남성 & A 011820 & \\
\hline Arisaema peninsulae Nakai & 점박이천남성 & E 50907 & \\
\hline Pinellia ternata (Thunb.) Ten. ex Breitenb. & 반하 & E 53023 & \\
\hline \multicolumn{4}{|l|}{ Acoraceae 창포과 } \\
\hline Acorus gramineus Sol. ex Aiton Hort. & 석창포 & P 150230 & II 등급종 \\
\hline
\end{tabular}


Appendix 1. Continued.

\section{Commelinaceae 닭의장풀과}

Commelina communis L.

Murdannia keisak (Hassk.) Hand.-Mazz.

\section{Juncaceae 골풀과}

Juncus effusus var. decipiens Buchenau

Juncus leschenaultii Gay ex Laharpe

Juncus papillosus Franch. \& Sav.

Juncus tenuis Willd.

Luzula capitata Kom.

\section{Cyperaceae 사초과}

Bulbostylis densa (Wall.) Hand.-Mazz.

Carex aphanolepis Franch. \& Sav.

Carex ligulata var. austrokoreensis Ohwi

Carex biwensis Ohwi

Carex bostrichostigma Maxim.

Carex breviculmis R. Br.

Carex capillacea Boott

Carex ciliatomarginata Nakai

Carex erythrobasis H. Lev. \& Vaniot

Carex forficula Franch. \& Sav.

Carex gibba Wahlenb.

Carex gifuensis Franch.

Carex japonica Thunb.

Carex lanceolata Boott

Carex leiorhyncha C. A. Mey.

Carex macroglossa Franch. \& Sav.

Carex maximowiczii Miq.

Carex mollicula Boott

Carex nervata Franch. \& Sav.

Carex neurocarpa Maxim.

Carex okamotoi Ohwi

Carex polyschoena H. Lev. \& Vaniot

Carex sabynensis (Franch. \& Sav.) Ohwi

Carex siderosticta Hance

Cyperus amuricus Maxim.

Cyperus difformis (Makino) T. Koyama

Cyperus globosus Forssk.

Cyperus iria Ohwi

Cyperus microiria Steud.

Cyperus orthostachyus Franch. \& Sav.

$\begin{array}{cc}\text { 닭의장풀 } & \text { E 71742 } \\ \text { 사마귀풀 } & \text { E } 90421 \\ \text { 골풀 } & \text { E } 60730 \\ \text { 참비녀골풀 } & \text { E } 71662 \\ \text { 청비녀골풀 } & \text { A } 053842 \\ \text { 길골풀 } & \text { E } 60729 \\ \text { 뀡의밥 } & \text { E } 71681\end{array}$

$\begin{array}{cc}\text { 꽃하늘지기 } & \text { A } 090907 \\ \text { 골사초 } & \text { P } 150564 \\ \text { 갈사초 } & \text { P } 150548\end{array}$

\section{솔잎사초}

A 081349

길뚝사초

P 150550

청사초

잔솔잎사초

털대사초

P 150475

한라사초

E 60753

산뚝사초

A 60751

나도별사초

A 099647

애기감둥사초

P 150551

P 150563

개찌버리사초

A 090222

A 090214

산갱이사초

A 081049

애기염주사초

왕비늘사초

A 105491

애기흰사초

갱이사초

지리대사초

가지청사초

Im. H. T. et al. 040344

C 150559

실청사초

P 150464

대사초

P 150465

방동사니

C 135240

알방동사니

E 71673

드렁방동사니

P 150461

참방동사니

금방동사니

I 013209

쇠방동사니
E 42535

E 41533

E 50908

E 41534

E 60749

E 71674

$\mathrm{VI}$ 등급종 적색목록(자료부족 [NE])

고유종, $\mathrm{II}$ 등급종

III 등급종

I 등급종

고유종, II 등급종

I 013212 
Appendix 1. Continued.

\begin{tabular}{|c|c|c|c|}
\hline Cyperus polystachyos Rottb. & 중방동사니 & C 0508 & \\
\hline Kyllinga brevifolia var. leiolepis (French \& Sav.) Franch. \& Sav. & 큰송이방동사니 & C 0504 & \\
\hline Scirpus wichurai var. asiaticus (Beetle) T. Koyama ex Ohwi & 방울고랭이 & A 090150 & \\
\hline \multicolumn{4}{|l|}{ Graminae 벼 과 } \\
\hline Agropyron ciliare (Trin.) Franch. & 속털개밀 & E 60741 & \\
\hline Agropyron tsukushiense var. transiens (Hack.) Ohwi & 개밀 & E 60733 & \\
\hline Alopecurus aequalis Sobol. & 뚝새풀 & E 60732 & \\
\hline Arthraxon hispidus (Thunb.) Makino & 조개풀 & $\mathrm{C} 0510$ & \\
\hline Arundinella hirta (Thunb.) Tanaka & 새 & P 150585 & \\
\hline Beckmannia syzigachne (Steud.) Fernald & 개피 & A 059555 & \\
\hline Bromus commutatus & 털큰참새귀리 & E 60740 & \\
\hline Bromus pauciflorus Hack. & 꼬리새 & E 60745 & \\
\hline Calamagrostis arundinacea (L.) Roth & 실새풀 & C 0513 & \\
\hline Cymbopogon tortilis subsp. goeringii (Steud.) T. Koyama & 개솔새 & C 0506 & \\
\hline Dactylis glomerata $\mathrm{L}$. & 오리새 & C 035070 & 외래식물 \\
\hline Digitaria sanguinalis (L.) Scop. & 바랭이 & E 71670 & \\
\hline Echinochloa crusgalli (L.) P. Beauv. & 돌피 & C 0507 & \\
\hline Eragrostis curvula (Schrad.) Nees & 능수참새그령 & E 60738 & 외래식물 \\
\hline Eragrostis ferruginea (Thunb.) P. Beauv. & 그령 & C 0511 & \\
\hline Eriochloa villosa (Thunb.) Kunth & 나도개피 & P 150480 & \\
\hline Festuca extremiorientalis Ohwi & 왕김의털아재비 & A 030883 & \\
\hline Festuca myuros L. & 들묵새 & A 059552 & 외래식물 \\
\hline Festuca parvigluma Steud. & 김의털아재비 & E 60744 & \\
\hline Hemarthria compressa var. japonica (Hack.) Y. N. Lee & 쇠치기풀 & A 030880 & \\
\hline Imperata cylindrica var. koenigii (Retz.) Benth. ex Pilg. & 띠 & E 60738 & \\
\hline Lolium multiflorum Lam. & 쥐보리 & E 60734 & 외래식물 \\
\hline Melica onoei Franch. \& Sav. & 쌀새 & Р 150598 & \\
\hline Milium effusum $\mathrm{L}$. & 나도겨이삭 & E 60736 & \\
\hline Miscanthus sinensis Andersson & 억새 & E 102445 & \\
\hline Oplismenus undulatifolius (Ard.) Roem. \& Schult. & 주름조개풀 & A 30881 & \\
\hline Paspalum thunbergii Kunth ex Steud. & 참새피 & С 0509 & \\
\hline Pennisetum alopecuroides (L.) Spreng. & 수크령 & C 0518 & \\
\hline Phalaris arundinacea $\mathrm{L}$. & 갈풀 & A 010669 & \\
\hline Poa acroleuca Steud. & 실포아풀 & E 41532 & \\
\hline Poa nipponica Koidz. & 큰꾸러미풀 & E 60739 & \\
\hline Poa trivialis $\mathrm{L}$. & 큰새포아풀 & C 035062 & \\
\hline Sacciolepis indica (L.) Chase & 좀물뚝새 & C 135254 & \\
\hline Sasa borealis (Hack.) Makino \& Shibata & 조릿대 & E 60741 & \\
\hline Setaria faberi R. A. W. Herrm. & 가을강아지풀 & A 010673 & \\
\hline Setaria glauca (L.) P. Beauv. & 금강아지풀 & C 0512 & \\
\hline Setaria viridis (L.) P. Beauv. & 강아지풀 & A 010671 & \\
\hline
\end{tabular}


Appendix 1. Continued.

Trisetum bifidum (Thunb.) Ohwi

\section{Typhaceae 부들과}

Typha orientalis C. Presl.

\section{Liliaceae 백합과}

Aletris spicata (Thunb.) Franch.

Allium macrostemon Bunge

Allium sacculiferum Y. N. Lee

Asparagus schoberioides Kunth

Convallaria keiskei Miq.

Disporum smilacinum A. Gray

Disporum uniflorum Baker

Erythronium japonicum Decne.

Hemerocallis fulva $\mathrm{L}$.

Hosta capitata (Koidz.) Nakai

Hosta longipes (Franch. \& Sav.) Matsum.

Hosta minor (Baker) Nakai

Lilium amabile Palib.

Lilium leichtlinii var. maximowiczii (Regel) Baker

Lilium tsingtauense Gilg

Liriope platyphylla F. T. Wang \& T. Tang

Liriope spicata (Thunb.) Lour.

Paris verticillata M. Bieb.

Polygonatum inflatum Kom.

Polygonatum lasianthum Maxim.

Polygonatum odoratum var. pluriflorum (Miq.) Ohwi

Smilacina japonica A. Gray

Tricyrtis macropoda Miq.

Tulipa edulis (Miq.) Baker

Veratrum maackii var. parviflorum (Maxim. ex Miq.) H. Hara

\section{Iridaceae 붓꽃과}

Iris ensata var. sponteana (Makino) Nakai

Iris minutoaurea Makino

Iris rossii Baker

\section{Smilacaceae 청미래덩굴과}

Smilax china L.

Smilax nipponica Miq.

Smilax riparia A. DC.

Smilax sieboldii Miq.

\section{Dioscoreaceae 마과}

Dioscorea quinqueloba Thunb.

Dioscorea tenuipes Franch. \& Sav.
잠자리피

A 010668
부들
C 134970

쥐

$\begin{array}{ccc}\text { 쥐꼬리풀 } & \text { C } 0519 & \text { III 등급종 } \\ \text { 산달래 } & \text { E } 53028 & \\ \text { 참산부추 } & \text { A } 010318 & \\ \text { 비짜루 } & \text { C } 135410 & \\ \text { 은방울꽃 } & \text { P } 150552 & \\ \text { 애기나리 } & \text { A } 867 & \\ \text { 윤판나물 } & \text { A } 010304 & \text { I 등급종 } \\ \text { 얼레지 } & \text { A } 010197 & \\ \text { 원추리 } & \text { E } 71749 & \text { I 등급종 } \\ \text { 일월비비추 } & \text { C } 0561 & \\ \text { 비비추 } & \text { E } 71665 & \text { III 등급종 } \\ \text { 좀비비추 } & \text { E } 41531 & \text { 고융, I 등급종 } \\ \text { 털중나리 } & \text { E } 53026 & \text { 고유종 } \\ \text { 중나리 } & \text { A } 010200 & \end{array}$

하늘말나리

A 010202

맥문동

A 010208

개맥문동

C 1353147

삿갓나물

A 010210

퉁둥굴레

E 53024

죽대

C 135076

둥굴레

C 0584

풀솜대

A 010217

뻐꾹나리

C 135379

산자고

E 41529

파란여로

C 0584

$\begin{array}{lcl}\text { 꽃창포 } & \mathrm{P} 150551 & \text { II 등급종 } \\ \text { 금붓꽃 } & \mathrm{E} 41536 & \text { II 등급종 }\end{array}$

각시붓꽃

P 150460

$\begin{array}{cc}\text { 청미래덩굴 } & \text { E } 71746 \\ \text { 선밀나물 } & \text { E } 71664 \\ \text { 밀나물 } & \text { A } 010220 \\ \text { 청가시덩굴 } & \text { E } 60758\end{array}$

단풍마 I 008255

각시마 $\quad$ C 135396 
Appendix 1. Continued.

\begin{tabular}{|c|c|c|c|}
\hline Orchidaceae 난과 & & & \\
\hline Cephalanthera longibracteata Blume & 은대난초 & E 53030 & \\
\hline Cremastra appendiculata (D. Don) Makino & 약난초 & A 011828 & $\begin{array}{c}\text { III등급종, } \\
\text { 적색목록(준위협[NT]) }\end{array}$ \\
\hline Cymbidium goeringii (Rchb. F.) Rchb. F. & 보춘화 & E 71754 & \\
\hline Epipactis thunbergii A. Gray & 닭의난초 & E 71751 & II 등급종 \\
\hline Gastrodia elata Blume & 천마 & I 011825 & $\mathrm{IV}$ 등급종 \\
\hline Liparis kumokiri F. Maek. & 옥잠난초 & A 011829 & \\
\hline Platanthera ussuriensis (Regel \& Maack) Maxim. & 나도잠자리난초 & E 53031 & II 등급종 \\
\hline
\end{tabular}

A; H. T. Im \& students / C; S. M. Choi, E. M. Sun \& B. A. Kim / E; H. T. Im \& H. H. Hong / I; H. T. Im / P; Im H. T. \& S. Y. Park 